University of Nebraska - Lincoln

DigitalCommons@University of Nebraska - Lincoln

U.S. Environmental Protection Agency Papers

U.S. Environmental Protection Agency

2009

Downstream variation in bankfull width of wadeable streams across the conterminous United States

John M. Faustini

Oregon State University, faustini.john@epa.gov

Philip R. Kaufmann

U.S. Environmental Protection Agency, kaufmann.phil@epa.gov

Alan T. Herlihy

Oregon State University, herlihy.alan@epa.gov

Follow this and additional works at: https://digitalcommons.unl.edu/usepapapers

Faustini, John M.; Kaufmann, Philip R.; and Herlihy, Alan T., "Downstream variation in bankfull width of wadeable streams across the conterminous United States" (2009). U.S. Environmental Protection Agency Papers. 100.

https://digitalcommons.unl.edu/usepapapers/100

This Article is brought to you for free and open access by the U.S. Environmental Protection Agency at DigitalCommons@University of Nebraska - Lincoln. It has been accepted for inclusion in U.S. Environmental Protection Agency Papers by an authorized administrator of DigitalCommons@University of Nebraska - Lincoln. 


\title{
Downstream variation in bankfull width of wadeable streams across the conterminous United States
}

\author{
John M. Faustini ${ }^{\text {a, } *}$, Philip R. Kaufmann ${ }^{\text {b }}$, Alan T. Herlihy ${ }^{\text {a }}$ \\ a Department of Fisheries and Wildlife, Oregon State University, Corvallis, OR 97331, USA \\ ${ }^{\mathrm{b}}$ U.S. Environmental Protection Agency, 200 SW 35th Street, Corvallis, OR 97333, USA
}

\section{A R T I C L E I N F O}

\section{Article history:}

Received 6 August 2008

Received in revised form 5 February 2009

Accepted 6 February 2009

Available online 12 February 2009

Keywords:

Downstream hydraulic geometry

Bankfull width

Anthropogenic disturbance

Wadeable streams assessment

United States

\begin{abstract}
A B S T R A C T
Bankfull channel width is a fundamental measure of stream size and a key parameter of interest for many applications in hydrology, fluvial geomorphology, and stream ecology. We developed downstream hydraulic geometry relationships for bankfull channel width $w$ as a function of drainage area $A, w=\alpha A^{\beta}$, (DHG $\left.\mathrm{DA}_{\mathrm{wA}}\right)$ for nine aggregate ecoregions comprising the conterminous United States using 1588 sites from the U.S. Environmental Protection Agency's National Wadeable Streams Assessment (WSA), including 1152 sites from a randomized probability survey sample. Sampled stream reaches ranged from 1 to $75 \mathrm{~m}$ in bankfull width and 1 to $10,000 \mathrm{~km}^{2}$ in drainage area. The $\mathrm{DHG}_{\mathrm{wA}}$ exponent $\beta$, which expresses the rate at which bankfull stream width scales with drainage area, fell into three distinct clusters ranging from 0.22 to 0.38 . Width increases more rapidly with basin area in the humid Eastern Highlands (encompassing the Northern and Southern Appalachians and the Ozark Mountains) and the Upper Midwest (Great Lakes region) than for the West (both mountainous and xeric areas), the southeastern Coastal Plain, and the Northern Plains (the Dakotas and Montana). Stream width increases least rapidly with basin area in the Temperate Plains (cornbelt) and Southern Plains (Great Prairies) in the heartland. The coefficient of determination $\left(r^{2}\right)$ was least in the noncoastal plains (0.36-0.41) and greatest in the Appalachians and Upper Midwest (0.68-0.77). $\mathrm{DHG}_{\mathrm{wA}}$ equations differed between streams with dominantly fine bed material (silt/sand) and those with dominantly coarse bed material (gravel/cobble/boulder) in six of the nine analysis regions. Where $\mathrm{DHG}_{\mathrm{wA}}$ equations varied by sediment size, fine-bedded streams were consistently narrower than coarse-bedded streams. Within the Western Mountains ecoregion, where there were sufficient sites to develop DHG $\mathrm{wA}_{\mathrm{w}}$ relationships at a finer spatial scale, $\alpha$ and $\beta$ ranged from 1.23 to 3.79 and 0.23 to 0.40 , respectively, with $r^{2}>0.50$ for 10 of 13 subregions (range: 0.36 to 0.92 ). Enhanced DHG equations incorporating additional data for three landscape variables that can be derived from GIS-mean annual precipitation, elevation, and mean reach slope-significantly improved equation fit and predictive value in several regions, most notably the Western Mountains and the Temperate Plains. Channel width was also related to human disturbance. We examined the influence of human disturbance on channel width using several indices of local and basinwide disturbance. Contrary to our expectations, the data suggest that the dominant response of channel width to human disturbance in the United States is a reduction in bankfull width in streams with greater disturbance, particularly in the Western Mountains (where population density, road density, agricultural land use, and local riparian disturbance were all negatively related to channel width) and in the Appalachians and New England (where urban and agricultural land cover and riparian disturbance were all negatively associated with channel width).
\end{abstract}

(c) 2009 Elsevier B.V. All rights reserved.

\section{Introduction}

The systematic variation of channel width $(w)$, mean flow depth $(d)$, and mean flow velocity $(v)$ with discharge $(Q)$ was termed "hydraulic geometry" by Leopold and Maddock (1953). Using gaging station data

\footnotetext{
* Corresponding author. Tel.: +1 541754 4581; fax: +1 5417544716.

E-mail addresses: faustini.john@epa.gov (J.M. Faustini), kaufmann.phil@epa.gov (P.R. Kaufmann), herlihy.alan@epa.gov (A.T. Herlihy).
}

from 20 large rivers in the Great Plains and southwestern United States, they found that simple power functions adequately described the dependence of these flow characteristics on discharge both at a cross section as discharge varies (at-a-section hydraulic geometry) and in the downstream direction (downstream hydraulic geometry, DHG) at a reference flow condition (e.g., bankfull discharge) within a river basin or specified geographic region. Subsequently, similar power function relationships with discharge have been reported for other channel characteristics including flow resistance and water surface slope (Leopold et al., 1964; Hey and Thorne, 1986; Knighton, 1998). 
DHG relationships are typically expressed as a simple power-law function of the type

$w=a Q^{b}$

where $a$ and $b$ are empirical coefficients from a log-log regression referred to as the hydraulic geometry coefficient and exponent, respectively. Deriving empirical DHG equations of the form expressed in Eq. (1) requires that discharge either be known from gaging station data or estimated using empirical relationships or other predictive models. However, gaging station data are often unavailable for particular streams of interest, and estimating discharge in ungaged streams can require significant data and effort and can be subject to considerable uncertainty. For these reasons, and because it can be useful to be able to predict bankfull channel dimensions in ungaged streams where the bankfull flow stage may not always be readily apparent in the field, some have advocated the development and use of regional DHG curves relating bankfull channel dimensions to drainage area $(A)$ in place of discharge (Leopold et al., 1964; Dunne and Leopold, 1978). These relationships take the form

$w=\alpha A^{\beta}$

where $\alpha$ and $\beta$ are empirical parameters. This formulation assumes that, within a limited geographic area having relatively uniform geology and climate, drainage area is the dominant control on discharge. Downstream hydraulic geometry relationships using $A$ as the independent variable generally exhibit more scatter than those based on $Q$ (Castro and Jackson, 2001; Soar and Thorne, 2001), but they allow one to make predictions of channel dimensions using only a digital elevation model (DEM). Such relationships have utility in applications such as preliminary channel design for restoration projects (Johnson and Fecko, 2008) and modeling habitat availability and suitability for fish in various life history stages (Rosenfeld et al., 2007).

This study uses a large $(n=1588)$ national data set to examine regional variations in DHG relationships for wadeable streams and rivers (those shallow enough to be wadeable at low flow) across the conterminous United States, focusing on bankfull channel width as a function of drainage area (hereafter $\mathrm{DHG}_{\mathrm{wA}}$ ). We chose to focus on bankfull width both because it is available in the data set (while mean bankfull depth and flow velocity are not) and because it is a fundamental measure of stream size and a key parameter of interest for many applications in hydrology, fluvial geomorphology, and stream ecology. Channel width has been found to be a predictor of annual bedload particle transport distance (Beechie, 2001) and of planform channel pattern and lateral migration dynamics (Beechie et al., 2006). Channel width is also a key factor controlling the dynamics and the morphological and process effects of large wood in streams (Nakamura and Swanson, 1993, 1994). From an ecological perspective, channel width is a measure of potential aquatic habitat area per unit stream length and is a fundamental control on structural and functional attributes of lotic ecosystems, such as the shift from a heterotrophic system in most headwater streams to an autotrophic system in most medium-sized rivers (Vannote et al., 1980).

Castro and Jackson (2001, p. 1250) noted that "[despite] extensive research in hydraulic geometry, there is surprisingly little data concerning regional relationships" and pointed out that existing regional hydraulic geometry equations, such as those of Leopold (1994), generally do not have well-defined geographic limits for their application. They compared three alternative stratification schemes for a regional DHG analysis using 76 gaging stations in the Pacific Northwest (Washington, Oregon, and Idaho), including stratification by climate zones, by physiographic provinces (Fenneman, 1946), and by ecoregions (Omernik, 1987). They reported that stratification by ecoregions best differentiated spatial variations in the recurrence interval for bankfull discharge. Doll et al. (2002) also used ecoregions to stratify DHG results in the Piedmont of North Carolina.

In this paper, we first explore the issue of how to define regional DHG relationships and assess whether the DHG concept can usefully be applied to broad geographic regions at the scale of water resources regions (Seaber et al., 1987) or the aggregated ecoregions used in the National Wadeable Streams Assessment (WSA) (USEPA, 2006) when using drainage area as the independent variable. The national data set we use (Paulsen et al., 2008a,b) is uniquely well-suited for this purpose. We then examine variations in $\mathrm{DHG}_{\mathrm{wA}}$ relationships among these broad geographical regions. Next we examine the influence of bed material size on $\mathrm{DHG}_{\mathrm{wA}}$ relationships within these regions and examine $\mathrm{DHG}_{\mathrm{wA}}$ relationships at a finer spatial scale within and among level III ecoregions (Omernik, 1987) comprising the topographically and climatically diverse Western Mountains ecoregion. We then use multiple regression methods to test whether the addition of other potential natural landscape controls on channel width that can be derived from available GIS data layers (specifically channel gradient, mean annual precipitation, and elevation) can yield improved regional predictive relationships for bankfull width. Finally, we assess whether regional $\mathrm{DHG}_{\mathrm{wA}}$ relationships are influenced by anthropogenic disturbance in two ways. First, we test whether $\mathrm{DHG}_{\mathrm{wA}}$ coefficient and exponent values differ between streams with the least amount of anthropogenic alteration and those with the greatest amount. Second, we use multiple regression to examine whether the residuals from the region-specific best predictive models for bankfull channel width are related to selected continuous variables that quantify watershed and riparian anthropogenic disturbance.

\section{Factors influencing the $\mathrm{DHG}_{\mathrm{wA}}$ relationship}

The DHG exponent for the width-discharge relationship (b) has commonly been reported or assumed to have a value of around 0.5 based on both empirical data and theoretical considerations (Knighton, 1998; Soar and Thorne, 2001). However, Park (1977) reported values ranging from 0.03 to 0.89 in a compilation of 72 DHG equations for river basins or regions, mainly in the United States and Great Britain but also including Puerto Rico, Malaysia, and Brazil, with most falling between 0.4 and 0.6. Bankfull discharge itself can be expressed as a power-law function of drainage area, i.e.,

$Q=x A^{y}$

Combining Eqs. (1)-(3), we can easily show that $\beta=y b$ and $\alpha=a \mathrm{x}^{\mathrm{b}}$. Because $y \leq 1$, most commonly in the range of 0.6 to 1.0 (Leopold et al., 1964; Knighton, 1987; Jennings et al., 1994; Mohamoud and Parmar, 2006), the width-area exponent $\beta$ is typically somewhat smaller than $b$. The discharge-area exponent $y$ reflects the rate at which discharge increases (typically) with increasing basin area and depends on basin shape (e.g., linear vs. dendritic), largely a function of regional geology (patterns of folding and faulting, etc.), as well as topography and climate. The width-area exponent $\beta$ quantifies the downstream rate of increase in width with increasing drainage area, which is predominantly determined by the downstream increase in discharge. Thus, $\beta$ is influenced by the same factors as $y$ in addition to downstream changes in width:depth ratio, channel gradient, and roughness-all of which influence the width for a given discharge. Strong orographic effects in mountainous regions, as well as high spatial variability in precipitation from localized storm systems, lead to high spatial gradients in precipitation and lower values of $\beta$; while uniform spatial patterns of precipitation (e.g., no orographic effect, large storm systems) lead to higher values of $\beta$. Arid zone streams in small- to medium-sized basins increase in width much faster than streams in humid climates, leading to higher values of $\beta$, perhaps from flashier flow regimes and longer recovery times for riparian vegetation, which work together to promote wider channels (Wolman and Gerson, 1978; 
Osterkamp, 1980; Knighton, 1998). Human impacts such as flow diversions, groundwater withdrawals, riparian vegetation alteration, changes in impervious area, and in-channel modifications can also affect the value of $\beta$.

The coefficient of the $\mathrm{DHG}_{\mathrm{wA}}$ relationship, $\alpha$, gives the predicted channel width for a basin of unit area (e.g., width in $\mathrm{m}$ for a $1 \mathrm{~km}^{2}$ basin). For two regions with the same exponent value $\beta$, the ratio $\alpha_{1} /$ $\alpha_{2}$ is the ratio of predicted channel width in region one to that in region two for basins of equal drainage area. The $\mathrm{DHG}_{\mathrm{wA}}$ coefficient $\alpha$ is related to precipitation (the greater the precipitation-or more specifically, runoff-the higher the value of $\alpha$ ), but can also be influenced by sediment size and quantity and by riparian vegetation. With respect to sediment size, channels with fine-grained, cohesive banks are generally narrower (lower $\alpha$ ) than channels with noncohesive banks (Knighton, 1998). The effect of vegetation is more ambiguous. Hey and Thorne (1986) reported coefficient values from width-discharge regressions for 62 stable gravel-bed rivers in the United Kingdom that decreased by nearly a factor of two with increasing woody vegetation, from 4.33 for streams with grassy banks to 2.34 for streams with $>50 \%$ tree/shrub cover. However, other researchers have reported on the basis of paired-reach studies that stream channel reaches with forested riparian zones are wider and have greater cross-sectional area than adjacent or nearly adjacent reaches lacking riparian forest cover (Trimble, 1997; Hession et al., 2003; Sweeney et al., 2004; Allmendinger et al., 2005). Anderson et al. (2004) attempted to reconcile these conflicting findings by suggesting that the influence of woody vs. grassy bank vegetation depends on the size of the stream. Anthropogenic impacts, both direct (e.g., channel straightening, removal of riparian vegetation and/or woody debris, rip-rapping, flow diversions) and indirect (e.g., augmented runoff in urban areas) can also influence channel width in either the positive or negative direction.

\section{Methods}

\subsection{Data set description}

\subsubsection{Sampling design}

The data used in this study were drawn from the U.S. Environmental Protection Agency's (USEPA) Wadeable Streams Assessment (WSA) (USEPA, 2006), which included 1392 sites selected using a spatially balanced random probability survey design (Stevens and Olsen, 1999, 2004; Herlihy et al., 2000). In addition, 522 hand-picked sites, typically selected by state or regional resource agency personnel to represent minimally disturbed, or "reference" conditions, were included in the initial data set. After screening the data to meet specific criteria (described later) for stream and basin size, data completeness, and data quality, we included 1152 probability (random) and 436 hand-picked sites in our analysis (Fig. 1). The WSA probability data set is a combination of two independent random samples, both of which were based on the perennial stream network in the National Hydrography Dataset (NHD) digitized from 1:100,000scale USGS topographic maps. Sites in 12 western states (excluding New Mexico but including North and South Dakota) were sampled between 2000 and 2004 as part of the EMAP Western Pilot study (Stoddard et al., 2005), while sites in the remaining 36 conterminous states were sampled during the summer of 2004. The target population for each sample differed slightly. In the western states, all perennial streams (excluding lower sections of the Columbia, Snake, Missouri, and Colorado Rivers) were included in the sample, and nonwadeable sites (not included in this study) were sampled using a different protocol than wadeable sites. In the eastern states, the target population from which the probability sample was drawn was restricted to first-through fifth-order perennial streams that could be sampled using wadeable protocols. In both cases, higher order streams were sampled at a higher frequency to ensure inclusion of adequate numbers of higher order sites in the sample. Field sampling protocols in the eastern and western states (Peck et al., 2006) were identical for all data used in this study.

\subsubsection{Site screening and quality assurance}

We limited our analysis to single-channel streams with bankfull widths between 1 and $75 \mathrm{~m}$, drainage areas between 1 and $10,000 \mathrm{~km}^{2}$, and average wetted width at time of sampling of at least $0.5 \mathrm{~m}$. Sites with $>25 \%$ bedrock within the wetted channel were excluded to limit our analysis to dominantly alluvial channels. Sites with incomplete data (missing or incomplete data for one or more key variables, including wetted and bankfull width, channel slope, and channel bed material) were also excluded. We also examined widthdrainage area scatter plots to identify potential outliers. For these sites we reviewed field sampling notes (and photos where available) and examined the sampling location using topographic mapping software and Google Earth. Sites that had obviously incorrect or unrepresentative drainage areas (because of incorrect coordinates, GIS errors, flow diversions, or interbasin transfers), were highly altered (e.g., flooded by a downstream dam, irrigation ditches), or had major data inconsistencies were excluded from the analysis (23 sites total).

\subsubsection{Field sampling methods and data compilation}

The WSA was designed to establish a baseline assessment of the ecological condition of wadeable streams at regional to national scales (USEPA, 2006; Paulsen et al., 2008b). Here we briefly summarize the methods used to collect relevant physical habitat data used in this study; further details are provided in Peck et al. (2006). All field-based site data reported here are reach-average values. Sample reach lengths were 40 times their summer season wetted width, but no less than $150 \mathrm{~m}$. Within each reach, data were collected at 11 equally spaced transects and associated $10 \mathrm{~m} \times 10 \mathrm{~m}$ (visually estimated) streamside riparian plots adjacent to each bank. Measurements at each transect included wetted and bankfull width and bankfull height above the low-flow water surface. Bankfull height was estimated in the field from channel bank and floodplain geometry, deposition features with fine sediments, riparian vegetation, and flood height evidence (see below). At and beyond each riparian plot, the presence and proximity of 11 categories of streamside human influences were recorded (row crops, pasture, dams and revetments, buildings, pavement, roadways, pipes, landfill or trash, parks/lawns, logging operations, and mining activities). Substrate size/type was visually classified in one of eight size classes (fine sediment, sand, fine gravel, coarse gravel, cobble, small boulder, large boulder, and bedrock/hardpan) or several nonsediment classes (wood, concrete, other) at 105 points within the sample reach (five equally spaced points within the wetted channel at each of the 11 transects plus 10 supplemental transects). Longitudinal measurements within each reach included reach slope (\%), calculated as the arithmetic mean of 10 water surface gradient measurements from hand-held clinometer sightings on survey rods between sequential pairs of transects, and a longitudinal survey of maximum (thalweg) depth at 100 equally spaced points (150 on streams $<2.5 \mathrm{~m}$ wide).

To characterize local riparian disturbance, a proximity-weighted riparian disturbance index, W1_HALL (Kaufmann et al., 1999, 2008) was calculated from the anthropogenic disturbance presence/absence data from the riparian plots by tallying the number of stations on both banks at which a particular type of disturbance was observed, weighting each observation according to its proximity to the stream, and then averaging over all 11 transects. A new index was calculated by normalizing W1_HALL to a $0-1$ scale (RIPDIS $=1-1 /[1+$ W1_HALL] $)$.

Estimation of bankfull stage at ungaged sites is to some degree inherently subjective. For this reason, EMAP sampling protocol and training were designed to minimize the potential for interpretational errors. Field crew training included classroom instruction, U.S. Forest Service videos (USFS, 1995, 2003), a detailed field manual (Peck et al., 


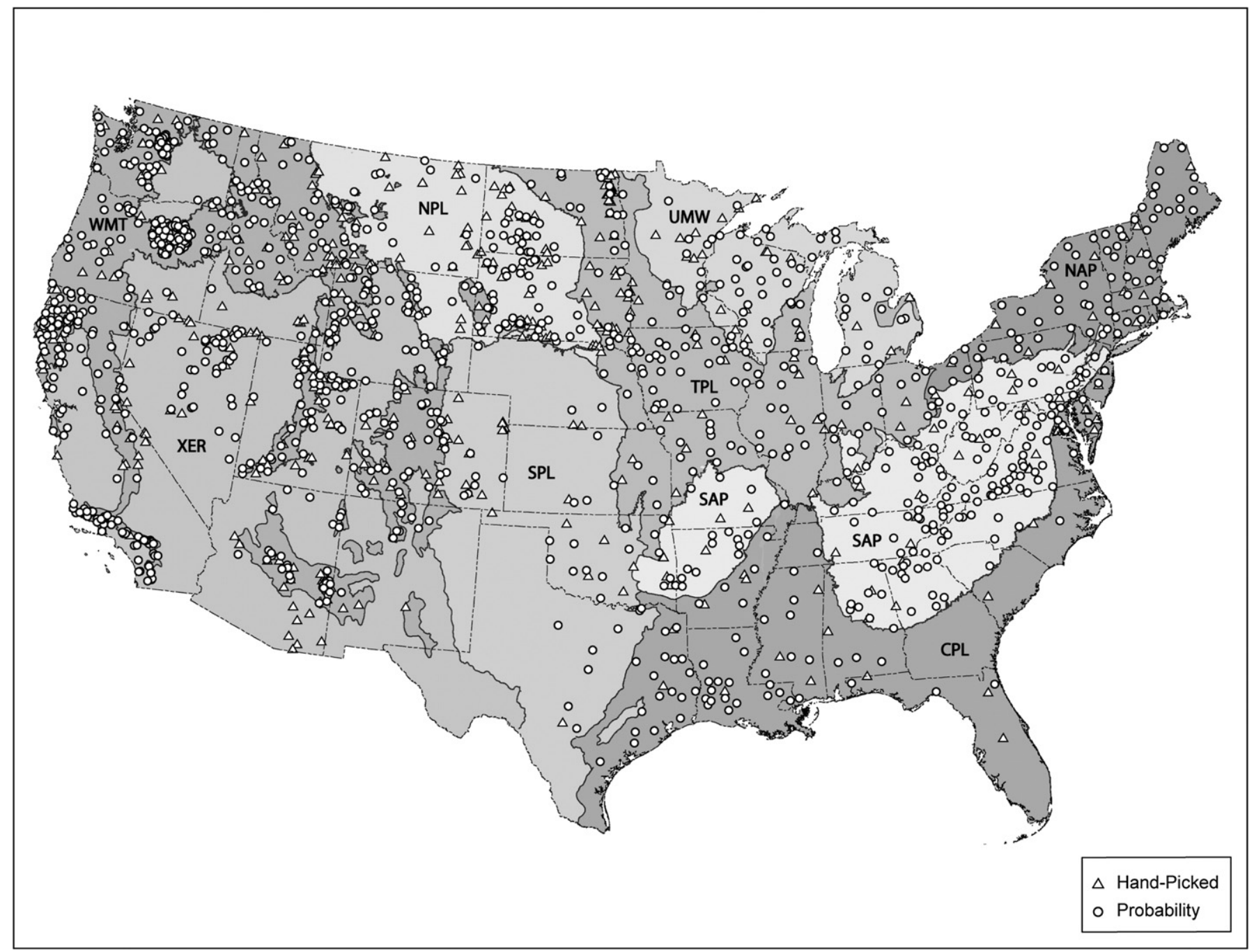

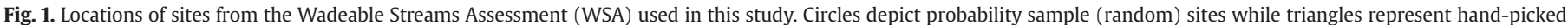

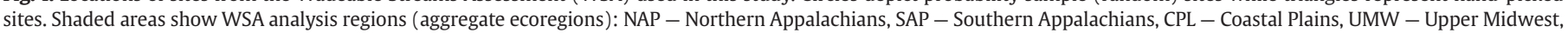
TPL - Temperate Plains, NPL - Northern Plains, SPL - Southern Plains, WMT - Western Mountains, XER - Xeric.

2006), and hands-on field training with experienced trainers in local streams. Field crews were instructed to first examine region-specific empirical curves of bankfull flow depth and width versus contributing drainage area (e.g., Dunne and Leopold, 1978; Castro and Jackson, 2001; Sweet and Geratz, 2003). Such curves provide a rough idea of where to look for field evidence to determine the level of bankfull flows in streams that are not greatly affected by hydrologic alterations (including flood magnitude increases associated with urban impervious areas, and flood decreases from dams and impoundments). At each transect where bankfull height and width were to be estimated, crews were instructed to look along both banks for indicators of bankfull stage, including morphological indicators (e.g., an obvious slope break indicating a transition from channel bank to floodplain surface), sedimentological indicators (e.g., tops of point bars or the upper/outer limit of exposed streambed sediments along channel margins), flow height indicators (evidence of scour, drift material caught on riparian vegetation, rocks, or woody debris along the banks), and vegetative indicators (moss growth on rocks, transition from bare sediments or flood-tolerant vegetation to flood-intolerant terrestrial vegetation). Field crews were instructed to favor morphological and depositional indicators where present. In the absence of clear bankfull indications, or in cases where the morphologic bank would contain clearly improbable floods, or is overtopped many times throughout the year, field crews were instructed to consider vege- tation and the previous season's flooding as the best evidence available (drift debris, deciduous leaf-fall, unvegetated sand, gravel, or mud deposits), keeping in mind the possibility of flow indicators well above bankfull stage following large floods.

\subsubsection{GIS-derived landscape metrics}

In addition to the field data, a number of GIS-based landscape metrics were calculated for each sampling location. Elevation and upstream drainage area for each sampling location (the midpoint or in some cases the downstream end of the sampled reach) were extracted from the National Elevation Dataset (NED). Mean annual precipitation at the sampling location was estimated using PRISM data gridded at a $2-\mathrm{km}$ resolution (Daly and Taylor, 2002). Percent watershed area with urban, agricultural, and forest cover were derived from the National Land Cover Dataset (NLCD 1992; available at http://landcover.usgs.gov/natllandcover.php). Population density (individuals $/ \mathrm{km}^{2}$ ) and road density $(\mathrm{km} /$ $\mathrm{km}^{2}$ ), which can both be regarded as indices of overall intensity of potential human landscape alteration, were estimated for the contributing watershed for each site based on data from the U.S. Census Bureau (1990, 2001).

\subsubsection{Disturbance level classification}

Water chemistry and physical habitat data were used to develop ecoregion-specific criteria to identify the least-disturbed reference 
sites in each ecoregion (Herlihy et al., 2008), as has been done in previous EMAP studies (Waite et al., 2000; Klemm et al., 2003). Whittier et al. (2007) described the process for classifying sites as least-disturbed, most-disturbed, and intermediate in the EMAP-West survey using four sets of ecoregion-specific criteria with a roundtable discussion to select a final list. Criteria included water quality (total P, total $\mathrm{N}, \mathrm{Cl}, \mathrm{SO}_{4}, \mathrm{pH}$, and turbidity), physical habitat (riparian disturbance, percent fine bed sediments or relative bed stability, and riparian vegetation), GIS-based measures of watershed disturbance (percent urban land, percent agricultural land, road density), and reconnaissance air photo analysis (disturbance scores based on the number, type, intensity, and proximity to the stream of human disturbances visible in aerial photographs). For the eastern stream sites, a similar process was used to identify least and most-disturbed sites based on ecoregion-specific criteria values for acid neutralizing capacity, sulfate, chloride, total nitrogen, total phosphorus, turbidity, percent fine sediment, EMAP riparian disturbance index, and EPA rapid bioassessment protocol habitat score (Herlihy et al., 2008).

\subsection{Analysis methods}

\subsubsection{Sampling precision}

We defined two statistical measures to assess the precision of fieldbased measurements of reach mean bankfull width and reach mean channel gradient. The root mean squared error (RMSE) is the pooled standard deviation $s$ of repeat measurements at randomly selected sites that were visited multiple times, either in the same sampling season or over multiple years. For a log-transformed variable (say, $\log w$ ) with an RMSE of $s$, the multiplicative standard deviation for repeat measurements $s^{*}=10^{s}$ provides a multiplicative measure of the precision of the untransformed variable (Limpert et al., 2001). That is, if $\log w$ has an RMSE of $s$, we state its precision as $\pm s$. The equivalent statement for precision of $w$ is $\times / \div$ (times/divided by) $s^{*}$. The second measure of precision we used is the signal-to-noise ratio, $S: N$, defined as the ratio of among-site variance to the variance of repeat measurements at the same site pooled among all sites with repeat measurements (Kaufmann et al., 1999). S:N provides a measure of the sensitivity of a measurement for purposes of detecting or characterizing among-site variations in the measured parameter (Faustini and Kaufmann, 2007).

\subsubsection{Regionalization of data set}

We compared two schemes for regionalizing the national WSA data set. The first regionalization scheme used the nine aggregate ecoregions (Fig. 1) used in the WSA study (USEPA, 2006) (hereafter referred to as WSA ecoregions or simply as ecoregions), which were constructed by aggregating level III ecoregions (Omernik, 1987). The second scheme used water resources regions, which comprise the first-level classification in the hierarchical hydrologic unit classification system developed by the USGS (Seaber et al., 1987) (Fig. 2). There are 18 water resources regions within the conterminous U.S., exactly double the number of WSA ecoregions. We used the coefficient of determination $\left(r^{2}\right)$ and RMSE to classify the fit of the $\mathrm{DHG}_{\mathrm{wA}}$ regression equations within a region as good $\left(r^{2} \geq 0.6\right.$ and RMSE $\left.\leq 0.18\right)$, moderate $\left(0.5 \leq r^{2}<0.6\right.$ and RMSE $\left.\leq 0.24\right)$, or poor $\left(r^{2}<0.5\right.$ or RMSE $>$ $0.24)$.

\subsubsection{Statistical analysis and modeling}

We used simple linear regression for log-transformed variables to quantify the DHG relation between bankfull channel width and drainage area, using log-transformed values of both variables, i.e., $\mu\{Y \mid$ $X\}=\beta_{0}+\beta_{1} X$, where $Y=\log w, X=\log A, w$ is bankfull width, $A$ is

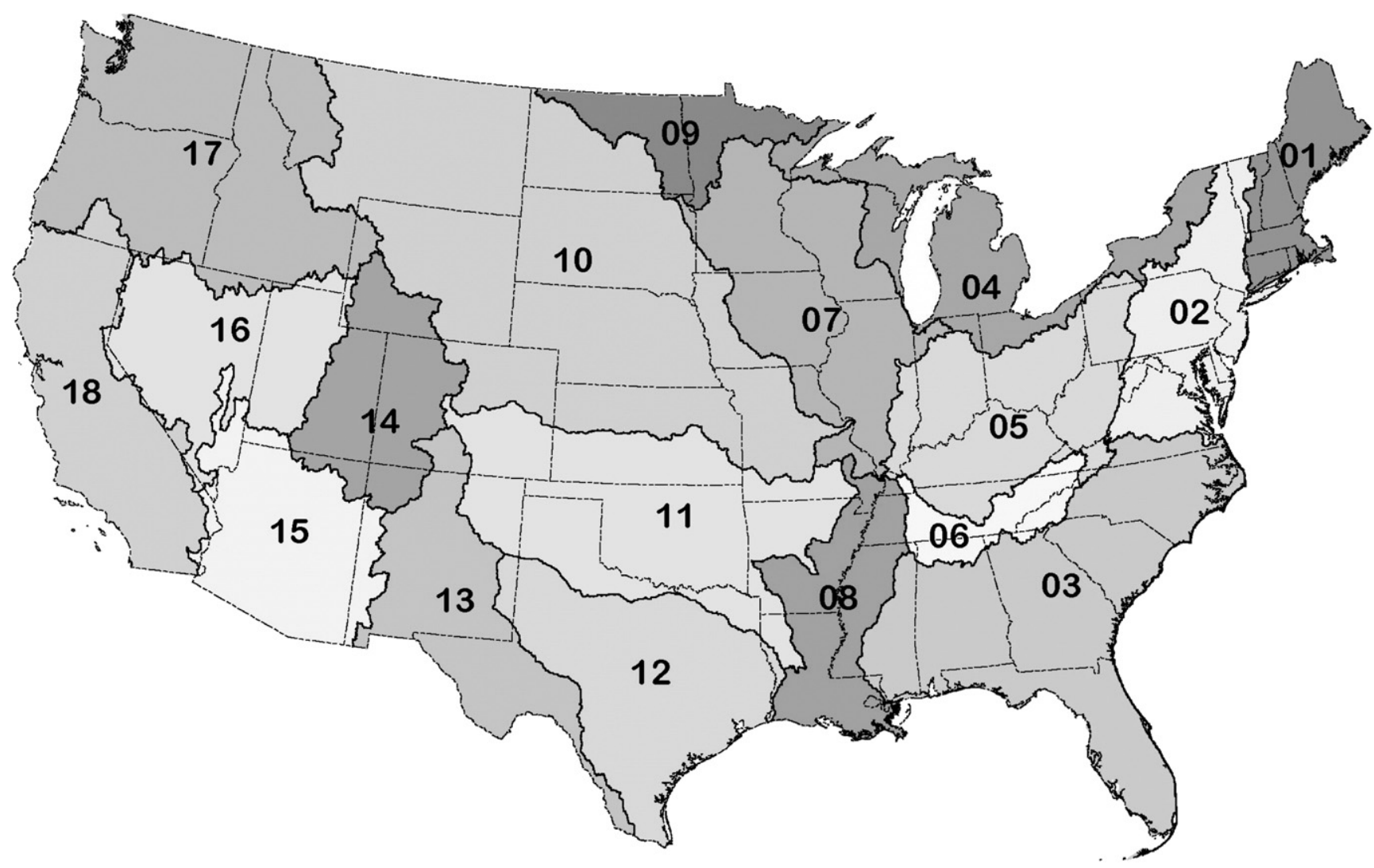

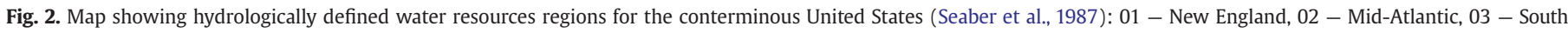

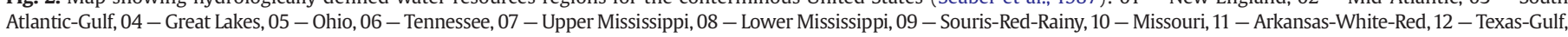
13 - Rio Grande, 14 - Upper Colorado, 15 - Lower Colorado, 16 - Great Basin, 17 - Pacific Northwest, 18 - California. 
upstream drainage area, and $\beta_{0}$ and $\beta_{1}$ are regression parameters (intercept and slope, respectively). Thus, the coefficient and exponent in the $\mathrm{DHG}_{\mathrm{wA}}$ relationship (Eq. (2)) are, respectively, $\alpha=10^{\beta 0}$ and $\beta=\beta_{1}$. We used analysis of variance (ANOVA) to estimate standard errors (SE) for the regression parameters and to test for significant differences among regions; we report these results in terms of the $\mathrm{DHG}_{\mathrm{wA}}$ parameters $\alpha$ and $\beta$. The SE that we report for $\alpha\left(\mathrm{SE}_{\alpha}^{*}\right)$ is thus a multiplicative SE, and a \pm 1 SE interval for $\alpha$ would be $\alpha \times / \div$ SE* (i.e., $\alpha / \mathrm{SE}_{\alpha}^{*}$ to $\alpha \times \mathrm{SE}_{\alpha}^{*}$ ) (Limpert et al., 2001). Note that if $\beta$ differs, then testing for a difference in $\alpha$ (i.e., that $\log \alpha_{1}-\log \alpha_{2} \neq 0$ or, equivalently, that $\alpha_{1} / \alpha_{2} \neq 1$ ) only answers the generally uninteresting question of whether expected bankfull width differs at a drainage area of $1 \mathrm{~km}^{2}$. Therefore, we report this test only when fitting a "parallel lines" regression model in which $\beta$ is constrained to be equal for groups in the comparison (Ramsey and Schafer, 2002), in which case $\alpha_{1} / \alpha_{2}$ can be interpreted as a measure of the average ratio of expected bankfull width for group 1 to that of group 2 across all basin sizes. We tested for differences in $\mathrm{DHG}_{\mathrm{wA}}$ parameters between streams with dominantly fine bed material $(<2 \mathrm{~mm})$ and those with dominantly coarse bed material to assess whether $\mathrm{DHG}_{\mathrm{wA}}$ relationships differed between gravel-bed streams and silt or sand-bed streams. (The WSA data set did not include information on bank material, so we used bed material as a proxy for bank material.) We also tested for differences in $\mathrm{DHG}_{\mathrm{wA}}$ parameters between the least-disturbed and most-disturbed sites within each region to assess potential impacts of anthropogenic disturbance on channel width.

We used multiple linear regression (MLR) to explore relationships between bankfull channel width and drainage area in combination with other potential controls on channel width that can be derived from available GIS data layers with national coverage and that were available in our data set. Specifically, we included mean annual precipitation and channel slope (primary controls on discharge and channel morphology, respectively), as well as elevation. (Our channel slope data were reach mean values derived from field data, but reach slope could be derived from digital elevation data in the absence of field data.) Within an ecoregion, elevation (in combination with drainage area) is primarily a proxy for site location on a headwaters-to-mouth continuum, though it might also serve to differentiate streams with snowmelt-dominated vs. rainfall-dominated hydrographs or to help the model to account for different precipitation-drainage area or slope-area relationships within a region (e.g., in the Coast Range vs. the Rocky Mountains within the Western Mountains ecoregion). We excluded the most-disturbed sites from this analysis in order to focus on natural landscape controls on channel width. For each region, we determined the best predictive model for bankfull width ("landscape effects model") based solely on bed material type and the aforementioned landscape variables. We included only those variables with parameter values significantly different from zero $(p<0.05)$ in the landscape effects model for each region. All variables except elevation were log-transformed, yielding a multiplicative effects model of the form

$w=\alpha A^{\beta} P^{q} S^{r} 10^{s Z}$

where $P$ is mean annual precipitation in $\mathrm{m}, S$ is mean reach slope, $Z$ is elevation above mean sea level ( $\mathrm{m}), \alpha$ is the antilog of the regression intercept, and $\beta, q, r$, and $s$ are regression parameters. We ranked models for each region using the Akaike information criterion (AIC) and selected the model with the lowest AIC value for which all the explanatory variables had $p$-values of 0.05 or less.

To assess potential effects of human disturbance on channel width, we first tested for differences in $\mathrm{DHG}_{\mathrm{wA}}$ parameters (from the bivariate channel width-basin area relationship) between the least-disturbed and most-disturbed sites within each region. In addition, building on the MLR analysis, we computed residuals (observed minus predicted values of $\log w$ ) from the landscape effects model for all sites (now including the most-disturbed sites), regressed the residuals against selected continuous measures of anthropogenic disturbance, and tested whether the regression coefficients for the disturbance variables were significant. In these regressions, we excluded sites for which the explanatory (disturbance) variable had zero values to avoid biasing the results by including large numbers of observations with zero values of the explanatory variable. To evaluate the potential magnitude of anthropogenic effects for continuous disturbance variables, we computed the difference of the residual of predicted $\log w$ at the 90th and 10th percentile values (P90 and P10) of the disturbance variable within a given region (after excluding zero and missing values) and backtransformed this quantity to obtain the predicted multiplicative effect on bankfull width of a change in the disturbance variable from the 10th to the 90th percentile value, all else being equal.

\section{Results and discussion}

\subsection{Precision of field measurements}

The RMSE of reach-average bankfull width measurements in the WSA data set was $1.8 \mathrm{~m}$ for revisits to the same site within a single sampling season and $2.6 \mathrm{~m}$ for all revisits, based on a total of 169 repeat visits (128 same year and 41 subsequent year revisits) to 102 different sites. The RMSE of $\log w$ was 0.055 for same-year visits and

Table 1

DHG equations and fit statistics for bankfull width vs. drainage area for the conterminous United States and alternate regionalization schemes ${ }^{\mathrm{a}}$.

\begin{tabular}{|c|c|c|c|c|c|c|c|c|}
\hline Region $^{\mathrm{b}}$ & $\alpha$ & $\mathrm{SE}_{\alpha}^{*}$ & $\beta$ & $\mathrm{SE}_{\beta}$ & RMSE & $r^{2}$ & $n$ & Fit \\
\hline Conterminous U.S. & 2.81 & 1.03 & 0.24 & 0.007 & 0.241 & 0.42 & 1588 & $P$ \\
\hline \multicolumn{9}{|l|}{ WSA Major Regions } \\
\hline Eastern highlands & 2.68 & 1.05 & 0.38 & 0.013 & 0.141 & 0.75 & 275 & G \\
\hline Plains and lowlands & 3.06 & 1.06 & 0.21 & 0.011 & 0.228 & 0.39 & 537 & $\mathrm{P}$ \\
\hline West & 2.27 & 1.05 & 0.28 & 0.011 & 0.243 & 0.44 & 776 & $\mathrm{P}$ \\
\hline \multicolumn{9}{|l|}{ WSA Aggregate Ecoregions } \\
\hline N. Appalachians (NAP) & 2.55 & 1.11 & 0.39 & 0.027 & 0.145 & 0.72 & 87 & G \\
\hline S. Appalachians (SAP) & 2.72 & 1.05 & 0.37 & 0.015 & 0.139 & 0.77 & 188 & G \\
\hline Coastal plain (CPL) & 2.63 & 1.09 & 0.29 & 0.025 & 0.161 & 0.60 & 88 & G \\
\hline Upper midwest (UMW) & 1.74 & 1.14 & 0.39 & 0.033 & 0.168 & 0.68 & 70 & G \\
\hline Temperate plains (TPL) & 3.26 & 1.11 & 0.22 & 0.020 & 0.214 & 0.40 & 181 & $\mathrm{P}$ \\
\hline Northern plains (NPL) & 1.45 & 1.21 & 0.28 & 0.029 & 0.237 & 0.41 & 137 & $\mathrm{P}$ \\
\hline outhern plains (SPL) & 2.31 & 1.25 & 0.23 & 0.039 & 0.233 & 0.36 & 61 & $P$ \\
\hline Western mountains (WMT) & 2.26 & 1.05 & 0.31 & 0.014 & 0.236 & 0.45 & 566 & $\mathrm{P}$ \\
\hline Xeric (XER) & 1.77 & 1.09 & 0.29 & 0.019 & 0.235 & 0.54 & 210 & $\mathbf{M}$ \\
\hline \multicolumn{9}{|l|}{ Water Resources Regions } \\
\hline New England (01) & 2.79 & 1.20 & 0.37 & 0.046 & 0.146 & 0.60 & 45 & G \\
\hline Mid-Atlantic & 2.57 & 1.09 & 0.38 & 0.025 & 0.141 & 0.75 & 77 & G \\
\hline South Atlantic-Gulf (03) & 2.40 & 1.11 & 0.36 & 0.032 & 0.153 & 0.68 & 60 & G \\
\hline Great Lakes (04) & 2.45 & 1.16 & 0.33 & 0.037 & 0.177 & 0.62 & 53 & G \\
\hline Ohio (05) & 3.02 & 1.08 & 0.33 & 0.021 & 0.133 & 0.77 & 80 & G \\
\hline Tennessee (06) & 1.97 & 1.17 & 0.44 & 0.060 & 0.154 & 0.68 & 27 & G \\
\hline Upper Mississippi (07) & 1.92 & 1.13 & 0.37 & 0.030 & 0.191 & 0.62 & 93 & $\mathbf{M}$ \\
\hline Lower Mississippi (08) & 2.95 & 1.14 & 0.27 & 0.035 & 0.128 & 0.67 & 30 & G \\
\hline Souris-Red-rainy (09) & 2.27 & 1.37 & 0.23 & 0.046 & 0.138 & 0.43 & 36 & $\mathrm{P}$ \\
\hline Missouri (10) & 2.33 & 1.10 & 0.23 & 0.017 & 0.262 & 0.37 & 317 & $\mathrm{P}$ \\
\hline Arkansas-white-red (11) & 3.43 & 1.19 & 0.23 & 0.035 & 0.257 & 0.38 & 72 & $\mathrm{P}$ \\
\hline Texas-Gulf (12) & 3.21 & 1.21 & 0.24 & 0.044 & 0.165 & 0.57 & 25 & G \\
\hline Rio Grande (13) & 2.17 & 1.56 & 0.14 & 0.116 & 0.292 & 0.10 & 15 & $\mathrm{P}$ \\
\hline Upper Colorado (14) & 2.99 & 1.19 & 0.22 & 0.036 & 0.246 & 0.34 & 72 & $P$ \\
\hline Lower Colorado (15) & 2.81 & 1.23 & 0.26 & 0.039 & 0.245 & 0.42 & 61 & $\mathrm{P}$ \\
\hline Great Basin (16) & 2.11 & 1.12 & 0.28 & 0.027 & 0.234 & 0.57 & 84 & M \\
\hline Pacific Northwest (17) & 2.00 & 1.08 & 0.34 & 0.023 & 0.252 & 0.43 & 270 & $\mathrm{P}$ \\
\hline California (18) & 2.49 & 1.08 & 0.27 & 0.022 & 0.188 & 0.48 & 171 & $\mathrm{P}$ \\
\hline
\end{tabular}

${ }^{\mathrm{a}}$ Here, $\alpha$ and $\beta$ are parameters in the relation $\log w=\log \alpha+\beta A$, where $w$ is bankfull channel width in $\mathrm{m}$ and $A$ is drainage area in $\mathrm{km}^{2} ; \mathrm{SE}_{\alpha}^{*}$ is the multiplicative standard error of $\alpha$; $\mathrm{SE}_{\beta}$ is the (additive) standard error of $\beta ; r^{2}$ is the coefficient of determination; $n$ is number of observations; and Fit is quality of the regression fit using the following criteria: Good: $r^{2} \geq 0.6$ and RMSE $\leq 0.18$; Mod.: $r^{2} \geq 0.5$ and RMSE $\leq 0.24$; Poor: $r^{2}<0.5$ or RMSE $>0.24$. Fit statistics for regressions with good or moderate fit are in boldface type.

b Value in parentheses is region code (for ecoregions; see Fig. 1) or number (for water resources regions; see Fig. 2). 
0.089 across all visits, which corresponds to multiplicative standard deviations $\left(s^{*}\right)$ for $w$ of $\times / \div 1.13$ and 1.23 , respectively. Corresponding $S: N$ values are 14 and 37, indicating that $\log w$ has sufficiently high precision that sampling error would have little impact on potential model fit (i.e., $r^{2}$ values) in regression modeling (Kaufmann et al., 1999; Faustini and Kaufmann, 2007). Mean reach slope $S$ had an RMSE of 0.0062 for within-year revisits, reflecting the relative imprecision of clinometer-based slope measurements, particularly for low-gradient streams. $\log S$ had an RMSE of $0.24\left(s^{*}=1.7\right)$ and an $S: N$ ratio of 4.4, indicating moderate precision (Kaufmann et al., 1999).

\subsection{Regionalization of data}

We compared two regionalization schemes for our national data set: the nine aggregated ecoregions (Fig. 1) used in the WSA study (USEPA, 2006) and water resources regions (Seaber et al., 1987) (Fig. 2). Table 1 summarizes regression results for log-transformed width vs. log-transformed drainage area under both regionalization schemes, as well as for the entire conterminous U.S. and for the three "major regions" for which results were reported in the WSA study (USEPA, 2006). Both approaches do about equally well in terms of subdividing the data set into regions with well-defined $\mathrm{DHG}_{\mathrm{wA}}$ relationships, with 5 of 9 ecoregions and 10 of 18 water resources regions (56\%) having "good" or "moderate" fit. Among WSA eco- regions, $r^{2}$ values ranged from 0.36 for the Southern Plains to 0.77 for the Southern Appalachians, while among water resources regions the range was 0.10 for the Rio Grande, which includes by far the fewest sites at 15 , to 0.77 for the Ohio (which is largely contained in the Southern Appalachians ecoregion). A surprisingly consistent and welldefined DHG relationship for bankfull width exists across the entire Appalachian region and New England. Both the coefficient and exponent of the $\mathrm{DHG}_{\mathrm{wA}}$ relationship for the Northern and Southern Appalachians are very similar (Table 1 ) and do not differ significantly $\left(p<0.01, t\right.$-test), and when both ecoregions are combined the $\mathrm{DHG}_{\mathrm{wA}}$ relationship has an $r^{2}$ of 0.75 .

Interestingly, both regionalization schemes yield poor $\left(r^{2}<0.5\right)$ $\mathrm{DHG}_{\mathrm{wA}}$ relationships for bankfull width for $44 \%$ of regions, and the hydrologically defined and more geographically compact water resources regions do no better than the WSA ecoregions in this regard, despite having generally a more than sufficient number of sites ( $n \geq 25$ for all but one region and $n \geq 45$ for 13 of 18 regions). In some cases, this may be due to overly broad aggregation of sites over large and/or geographically dispersed regions (e.g., the Missouri water resources region or the Western Mountains ecoregion), but some relatively compact regions also exhibit poor $\mathrm{DHG}_{\mathrm{wA}}$ relationships for bankfull width (e.g., the Northern Plains ecoregion (Fig. 1) and the Upper and Lower Colorado water resource regions) (Fig. 2; Table 1). In these regions it may be that inherent spatial variability in natural

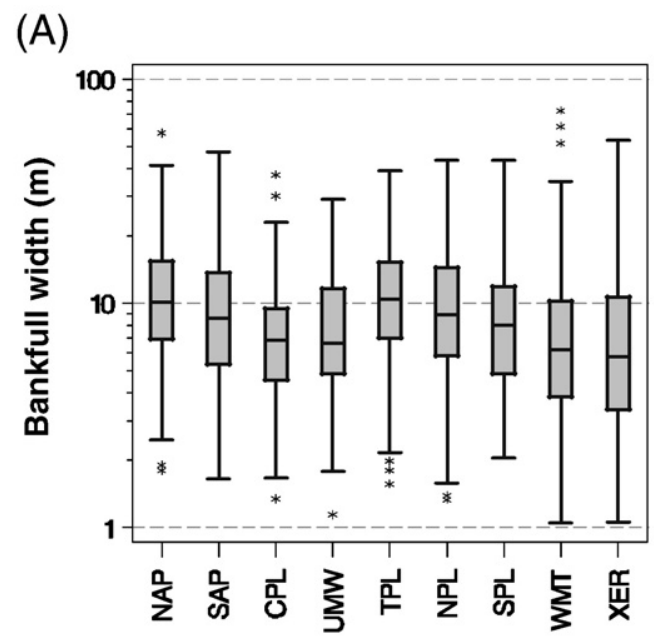

(C)

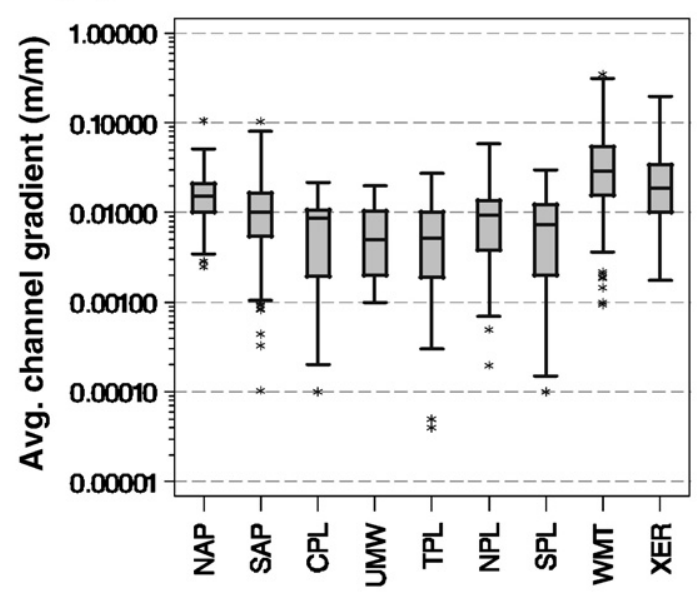

Aggregate ecoregion
(B)

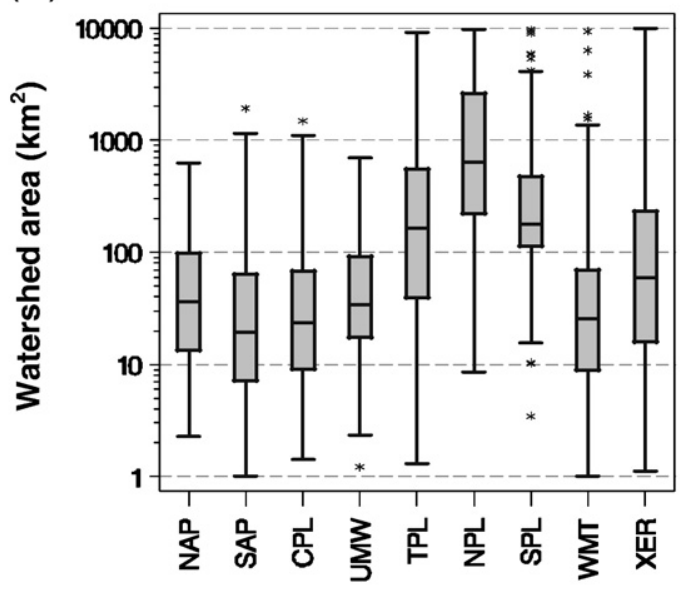

(D)

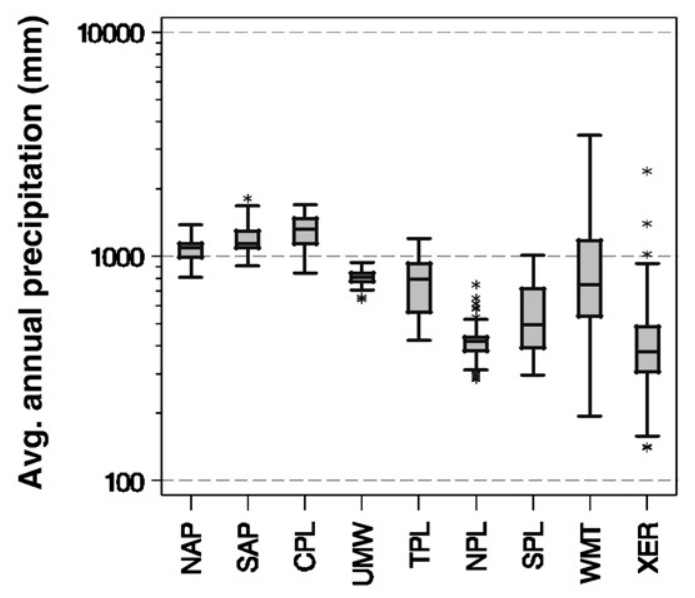

Aggregate ecoregion

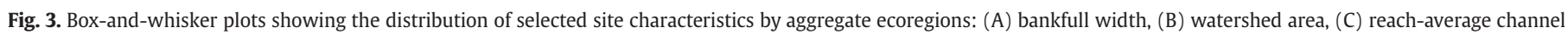
gradient, (D) mean annual precipitation at sampling location. 
controls such as geology, topography and climate, and/or spatial variability in anthropogenic hydrologic alterations (e.g., diversions, channel modification, etc.) prevents the development of well-defined $\mathrm{DHG}_{\mathrm{wA}}$ relationships. Because both regionalization schemes appear to work about equally well, we chose to use the more parsimonious WSA ecoregions for the remainder of our analysis.

\section{3. $D H G_{W A}$ results by WSA ecoregions}

In this section we discuss DHG relationships within and among the WSA ecoregions in more detail. First, we briefly examine variations among WSA ecoregions in the two variables that define the DHG relation on which we have chosen to focus, bankfull width and
(A) NAP

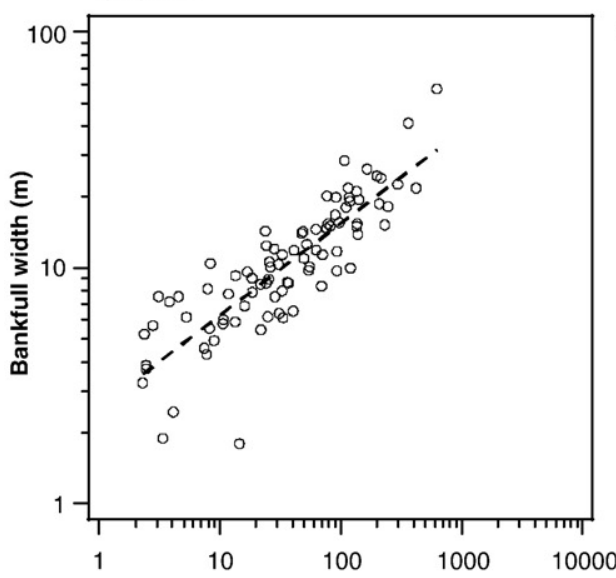

(D) UMW

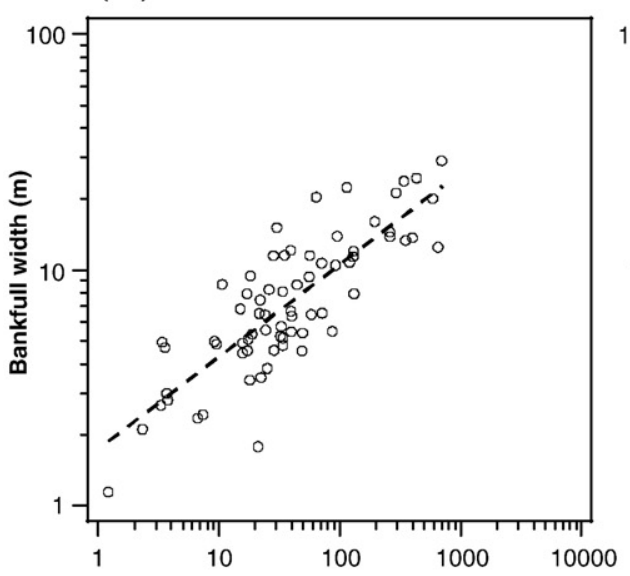

(G) SPL

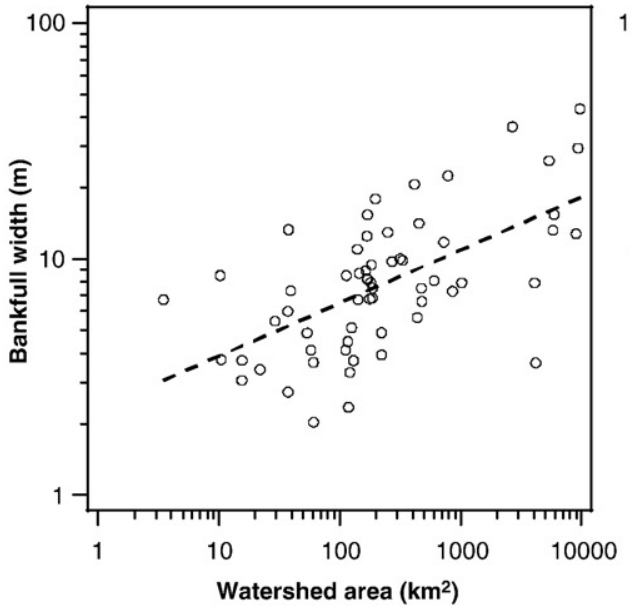

(B) SAP

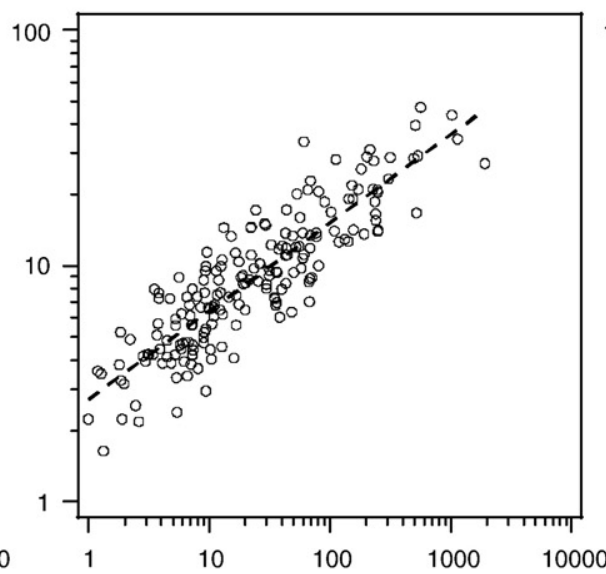

(E) TPL

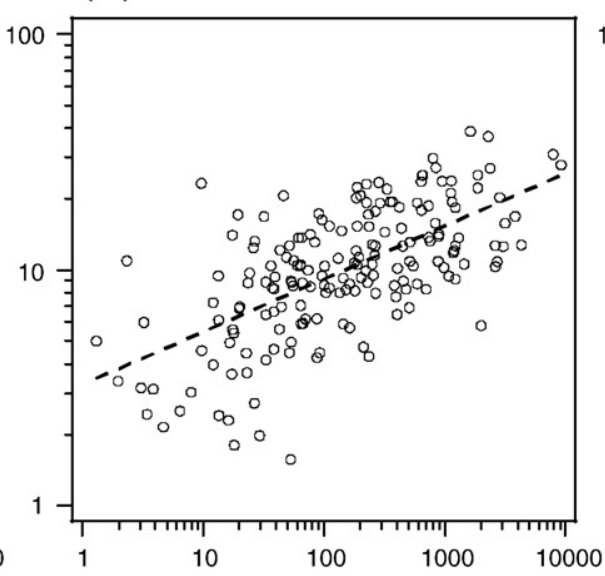

(H) WMT

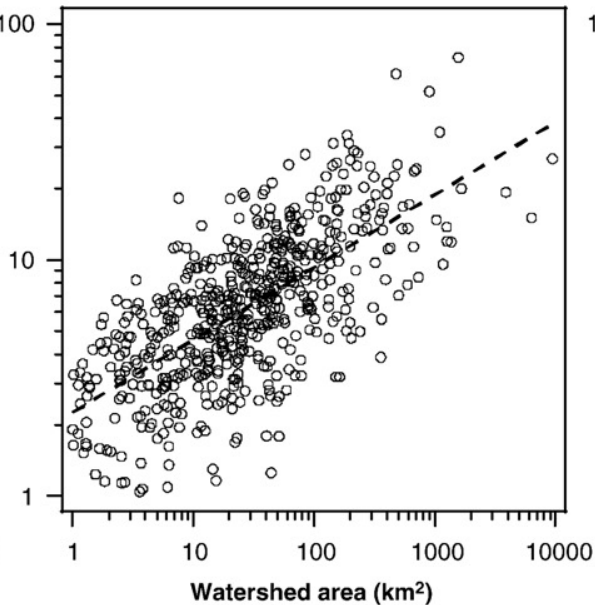

(C) $\mathrm{CPL}$

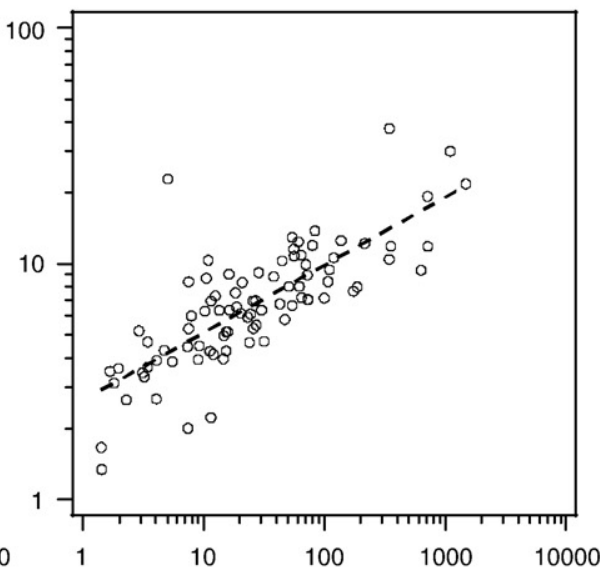

(F) NPL

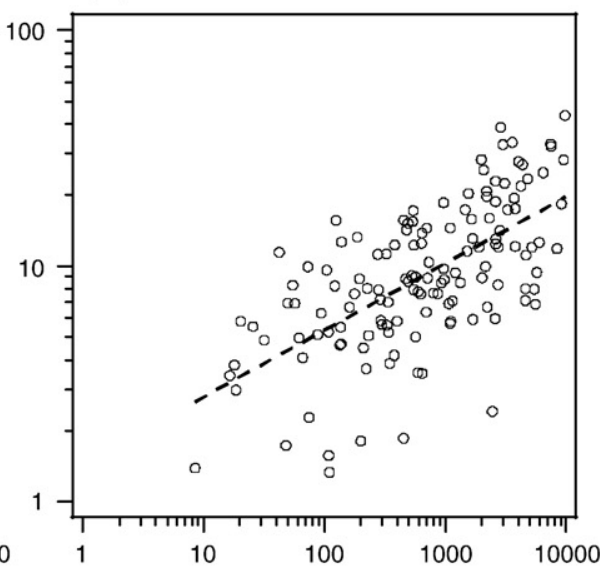

(I) XER

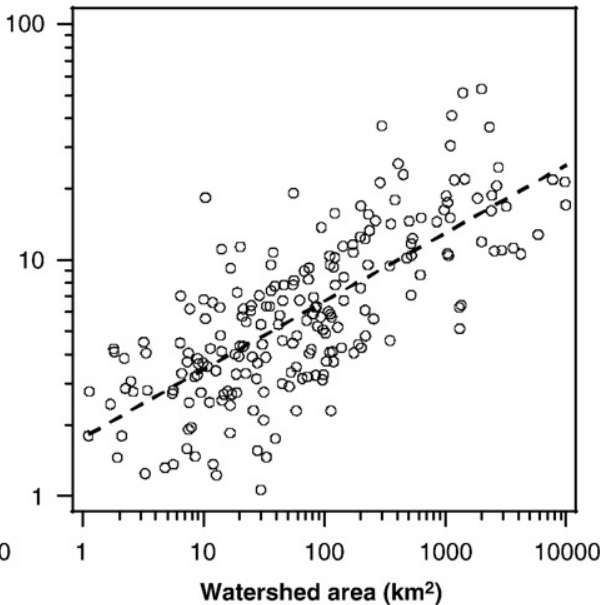

Fig. 4. Bankfull width vs. drainage area for nine WSA ecoregions. Dashed line shows regression fit for each region. Regression equations and fit statistics are given in Table 1. 
Table 2

Regression coefficients for width vs. drainage area $\left(w=\alpha A^{\beta}\right)$ from selected published studies .

\begin{tabular}{|c|c|c|c|c|c|c|}
\hline Source & $\alpha$ & $\beta$ & $r^{2}$ & $n$ & $A\left(\mathrm{~km}^{2}\right)$ & Location \\
\hline Hession et al. (2003) & & & & & & SE Pennsylvania \\
\hline Forested urban & 5.83 & 0.13 & 0.45 & 10 & $0.4-50$ & Piedmont \\
\hline Nonforested urban & 3.86 & 0.12 & 0.24 & 10 & $0.4-50$ & \\
\hline Forested nonurban & 4.15 & 0.30 & 0.82 & 16 & $0.7-15$ & \\
\hline Nonforested nonurban & 1.97 & 0.46 & 0.91 & 16 & $0.7-15$ & \\
\hline Doll et al. (2002) & & & & & & North Carolina \\
\hline Urban & 5.43 & 0.33 & 0.88 & 17 & $0.4-100$ & Piedmont \\
\hline Rural & 3.14 & 0.36 & 0.91 & 13 & $0.5-300$ & \\
\hline Sweet and Geratz (2003) & 2.94 & 0.38 & 0.95 & 22 & $1.6-470$ & $\begin{array}{l}\text { North Carolina } \\
\text { coastal plain }\end{array}$ \\
\hline $\begin{array}{l}\text { Golden and Springer (2006) } \\
\text { b }\end{array}$ & 4.76 & 0.33 & 0.93 & 32 & $0.5-9.6$ & $\begin{array}{l}\text { West Virginia } \\
\text { Appalachian } \\
\text { plateau }\end{array}$ \\
\hline \multicolumn{7}{|l|}{ Johnson and Fecko (2008) } \\
\hline Coastal plain & 2.21 & 0.38 & & 66 & $\sim 1-1000$ & $\begin{array}{l}\mathrm{DE} / \mathrm{MD} / \mathrm{NC} / \mathrm{AL} / \\
\mathrm{FL}\end{array}$ \\
\hline Piedmont & 2.94 & 0.39 & & 36 & $\sim 1-1000$ & $\mathrm{MD} / \mathrm{NC}$ \\
\hline $\begin{array}{l}\text { Appalachian plateau, } \\
\text { valley and ridge, } \\
\text { New England }\end{array}$ & 2.65 & 0.45 & & 154 & $\sim 1-1000$ & $\begin{array}{l}\mathrm{NY} / \mathrm{PA} / \mathrm{MD} / \mathrm{VA} / \\
\mathrm{WV} / \mathrm{NC}\end{array}$ \\
\hline \multicolumn{7}{|c|}{ Mohamoud and Parmar $(2006)^{c}$} \\
\hline Appalachian plateau & 2.26 & 0.41 & & 25 & $32-1030$ & $\mathrm{PA} / \mathrm{MD} / \mathrm{WV} / \mathrm{VA}$ \\
\hline Ridge and valley & 1.96 & 0.40 & & 25 & 9-981 & $\mathrm{PA} / \mathrm{WV} / \mathrm{VA}$ \\
\hline Piedmont & 1.66 & 0.46 & & 25 & $6-839$ & $\mathrm{PA} / \mathrm{MD} / \mathrm{VA}$ \\
\hline Moody et al. (2003) ${ }^{d}$ & & & & 191 & & \\
\hline Plains & 3.7 & 0.36 & 0.71 & & $\sim 80-2.6 \times 10^{5}$ & $\begin{array}{l}\text { Ohio and } \\
\text { Missouri R. }\end{array}$ \\
\hline Mountains & 3.3 & 0.41 & 0.60 & & $\sim 15-1.3 \times 10^{6}$ & $\begin{array}{l}\text { Upper Missouri } \\
\text { and Columbia R. }\end{array}$ \\
\hline Castro and Jackson (2001) & & & & & & Oregon, \\
\hline Pacific Northwest & 3.60 & 0.38 & 0.49 & 76 & $46-20,930$ & Washington, \\
\hline Pacific Maritime mtns. & 3.78 & 0.43 & 0.59 & 22 & & and Idaho \\
\hline Basin and range & 1.00 & 0.51 & 0.83 & 22 & & \\
\hline Western Cordillera & 2.87 & 0.42 & 0.54 & 32 & & \\
\hline
\end{tabular}

a Where original units differed, values have been converted to units of width in $\mathrm{m}$ and area in $\mathrm{km}^{2}$

b Multiple reaches $(\leq 7)$ surveyed within each of 32 basins, 157 in total; regression performed on log-binned data in nine watershed area size classes.

c Parameters calculated from data in their Tables 2 and 3.

d Based on width measurements from the Lewis and Clark expedition, 1803-1805.

drainage area, and in key topographic and climate variables that can influence the $\mathrm{DHG}_{\mathrm{wA}}$ relationship, specifically channel gradient and mean annual precipitation. Next we examine differences in $\mathrm{DHG}_{\mathrm{wA}}$ parameters among ecoregions, and finally we evaluate the importance of sediment size on regional $\mathrm{DHG}_{\mathrm{wA}}$ relationships.

\subsubsection{Regional variation in channel and watershed characteristics of sampled streams}

The distribution of bankfull widths was generally similar among ecoregions in our sample, although there was a greater proportion of narrower streams in the west (Western Mountains and Xeric ecoregions) than elsewhere (Fig. 3A). Watershed area was more variable among ecoregions, with the noncoastal plains ecoregions (TPL, NPL, SPL) generally having significantly greater watershed areas upstream of sampled locations than other regions, including many streams with drainage areas $>1000 \mathrm{~km}^{2}$ (Fig. 3B). Not surprisingly, average channel gradient was greatest in mountainous and high-elevation ecoregions (Fig. 3C). Half of all sampled streams in the Southern Appalachians ecoregion and more than three-quarters of sampled streams in the Northern Appalachians, Western Mountains, and Xeric ecoregions had slopes of $\geq 1.0 \%$. A majority of sampled streams in the Northern and Southern Plains and three-quarters of sampled streams in the remaining flatland ecoregions (Coastal Plains, Upper Midwest, and Temperate Plains) had channel slopes of $\leq 1.0$ percent. Average annual precipitation at sampled sites exhibited considerable variation among WSA ecoregions (Fig. 3D). The relationship among ecoregions for precipitation was roughly inverse to that for watershed area, with lower precipitation in ecoregions that had the largest watershed areas (i.e., the Xeric ecoregion and the Temperate, Northern, and Southern Plains ecoregions). Among-site variation in mean annual precipitation was lowest in the Upper Midwest and Northern Plains ecoregions and was also low in the Northern and Southern Appalachians and the Coastal Plain ecoregions, while among-site variability was much greater in the Western Mountains and Xeric ecoregions.

\subsubsection{Variation in regression parameters and model fit among ecoregions}

The exponent $\beta$ in the $\mathrm{DHG}_{\mathrm{wA}}$ relationship for the WSA ecoregions varied between 0.22 and 0.39 , while the coefficient of determination ranged from 0.36 to 0.77 (Table 1). The easternmost ecoregions (NAP, SAP, CPL, UMW) exhibited the least data scatter and highest $r^{2}$ values (Fig. 4; Table 1). For regions where the fit of regression models was good $\left(r^{2} \geq 0.6\right.$ and RMSE $\left.\leq 0.18\right)$ or moderate $\left(0.5 \leq r^{2}<0.6\right.$ and RMSE $\leq 0.24$ ), the range of exponent values was 0.29 to 0.39 . Other researchers have generally reported $\beta$ values between 0.30 and 0.46 (Table 2). Where they overlap geographically, the $\beta$ values we found tended to be at the low end of those reported by others. For example, we report $\beta$ values of 0.37 and 0.39 for the Southern and Northern Appalachians, respectively, while Johnson and Fecko (2008) and Mohamoud and Parmar (2006) reported ranges of $0.39-0.45$ and $0.40-0.46$, respectively, for portions of the same region (Table 2).

The WSA ecoregions can be divided into three groups on the basis of their width-area exponent values-i.e., those with low, intermediate, and high $\beta$ values. The Temperate Plains and Southern Plains

Table 3

Estimated DHG coefficient and exponent values for bankfull channel width vs. drainage area by WSA ecoregions, parallel lines model ${ }^{\mathrm{a}}$.

\begin{tabular}{|c|c|c|c|c|c|c|}
\hline Region(s) & Parameter $^{\mathrm{b}}$ & Estimate & Std. error ${ }^{c}$ & $r^{2}$ & $n$ & $\overline{p \text {-value }}{ }^{\mathrm{d}}$ \\
\hline \multicolumn{7}{|l|}{ Group 1: $\beta=0.22$} \\
\hline TPL, SPL & $\beta$ & 0.22 & 0.018 & & 242 & \\
\hline TPL & $\alpha$ & 3.26 & 1.100 & 0.40 & 181 & \\
\hline SPL & $\alpha$ & 2.32 & 1.121 & 0.36 & 61 & \\
\hline TPL vs. SPL & $\alpha_{T P L} / \alpha_{S P L}$ & 1.41 & 1.076 & & 242 & $<0.0001$ \\
\hline \multicolumn{7}{|l|}{ Group 2: $\beta=0.30$} \\
\hline CPL, NPL, WMT, XER & $\beta$ & 0.30 & 0.009 & & 1001 & \\
\hline $\mathrm{CPL}$ & $\alpha$ & 2.55 & 1.062 & 0.60 & 88 & \\
\hline NPL & $\alpha$ & 1.32 & 1.320 & 0.41 & 137 & \\
\hline WMT & $\alpha$ & 2.33 & 1.037 & 0.45 & 566 & \\
\hline XER & $\alpha$ & 1.70 & 1.053 & 0.54 & 210 & \\
\hline CPL vs. NPL & $\alpha_{C P L} / \alpha_{N P L}$ & 1.93 & 1.076 & & 225 & $<0.0001$ \\
\hline CPL vs. WMT & $\alpha_{C P L} / \alpha_{W M T}$ & 1.09 & 1.058 & & 654 & 0.12 \\
\hline CPL vs. XER & $\alpha_{C P L} / \alpha_{X E R}$ & 1.49 & 1.065 & & 298 & $<0.0001$ \\
\hline WMT vs. NPL & $\alpha_{W M T} / \alpha_{N P L}$ & 1.77 & 1.057 & & 703 & $<0.0001$ \\
\hline XER vs. NPL & $\alpha_{X E R} / \alpha_{N P L}$ & 1.29 & 1.059 & & 347 & $<0.0001$ \\
\hline WMT vs. XER & $\alpha_{W M T} / \alpha_{X E R}$ & 1.37 & 1.041 & & 776 & $<0.0001$ \\
\hline \multicolumn{7}{|l|}{ Group 3: $\beta=0.38$} \\
\hline APP, UMW & $\beta$ & 0.38 & 0.018 & & 345 & \\
\hline APP & $\alpha$ & 2.66 & 1.068 & 0.75 & 275 & \\
\hline UMW & $\alpha$ & 1.80 & 1.091 & 0.68 & 70 & \\
\hline APP vs. UMW & $\alpha_{A P P} / \alpha_{U M W}$ & 1.47 & 1.068 & & 345 & $<0.0001$ \\
\hline
\end{tabular}

a Regression model is $\log w=(\log A) \times$ Group Region, where Region is WSA ecoregion as shown in Fig. 1 (except that the NAP and SAP regions have been combined into the APP region) and Group is a three-level class variable that groups regions according to DHG exponent value, $\beta$. Regions within each level of Group had similar values of $\beta$ (Table 1). Within each level of Group, $\beta$ was constrained to a single value but the DHG coefficient $\alpha$ was allowed to vary among regions. Differences among $\beta$ values between levels of Group are highly significant $(p<0.001)$.

b Parameters: $\alpha$ is the coefficient and $\beta$ is the exponent from the DHG relationship, $w=\alpha A^{\beta}$, where $\beta$ is the slope parameter and $\log \alpha$ is the intercept from the regression model. Ratios of DHG coefficient values (e.g., $\alpha_{\mathrm{NPL}} / \alpha_{\mathrm{XER}}$ ) are given for regions within the same group (which have the same value of $\beta$ ), where it can be interpreted as the ratio of the average bankfull width in the two regions at any value of $A$. Thus, streams in the Appalachians (APP) are approximately 50\% wider than streams of the same drainage area in the Upper Midwest (UMW), since $\alpha_{\mathrm{APP}} / \alpha_{\mathrm{UMW}}=1.47$.

c SE estimates for $\beta$ are additive $( \pm)$, while SE estimates for $\alpha$ and $\alpha$ ratios are multiplicative $(\times / \div)$.

${ }^{\mathrm{d}}$ From $t$-test for zero difference between intercept parameter $(\log \alpha)$ values. 
Table 4

DHG equations and fit statistics for bankfull width vs. drainage area by WSA ecoregions for fine (FN) vs. coarse (CS) bed material.

\begin{tabular}{|c|c|c|c|c|c|c|c|c|c|c|c|c|c|c|c|c|c|}
\hline \multirow[t]{2}{*}{ Region } & \multirow{2}{*}{$\begin{array}{l}\text { Model } \\
\text { type }^{a}\end{array}$} & \multirow{2}{*}{$\begin{array}{l}\text { Bed } \\
\text { type }\end{array}$} & \multirow[t]{2}{*}{$\alpha$} & \multirow[t]{2}{*}{$\mathrm{SE}_{\alpha}^{*}$} & \multirow[t]{2}{*}{$\beta$} & \multirow[t]{2}{*}{$\mathrm{SE}_{\beta}$} & \multirow{2}{*}{$\begin{array}{l}p \text {-value } \\
\text { for } \Delta \beta^{\text {b }}\end{array}$} & \multicolumn{3}{|c|}{ Coeff. ratio, $a_{\mathrm{cs}} / a_{\mathrm{fn}}{ }^{c}$} & \multicolumn{3}{|c|}{ Fit statistics by FN/CS } & \multicolumn{3}{|c|}{ Overall fit statistics } & \multirow{2}{*}{$\begin{array}{l}\text { Model } \\
\mathrm{fit}^{\mathrm{d}}\end{array}$} \\
\hline & & & & & & & & $\overline{\text { Est. }}$ & SE & $p$-value & $\overline{\mathrm{RMSE}}$ & $r^{2}$ & $n$ & $\overline{\text { RMSE }}$ & $r^{2}$ & $n$ & \\
\hline$\overline{\mathrm{NAP}}$ & single & $\mathrm{FN}+\mathrm{CS}$ & 2.56 & 1.106 & 0.39 & 0.027 & 0.06 & & & & & & & 0.145 & 0.72 & 87 & G \\
\hline \multirow[t]{2}{*}{ SAP } & p-lines & FN & 2.15 & 1.066 & 0.38 & 0.014 & 0.78 & 1.35 & 1.053 & $<0.0001$ & 0.100 & 0.88 & 43 & 0.128 & 0.80 & 188 & G \\
\hline & & CS & 2.89 & 1.051 & & & & & & & 0.135 & 0.77 & 145 & & & & G \\
\hline $\mathrm{CPL}$ & single & $\mathrm{FN}+\mathrm{CS}$ & 2.63 & 1.095 & 0.29 & 0.025 & 0.41 & & & & & & & 0.161 & 0.60 & 88 & G \\
\hline UMW & single & $\mathrm{FN}+\mathrm{CS}$ & 1.74 & 1.137 & 0.39 & 0.033 & 0.58 & & & & & & & 0.168 & 0.68 & 70 & G \\
\hline \multirow[t]{2}{*}{ TPL } & s-lines & FN & 2.65 & 1.120 & 0.25 & 0.021 & 0.01 & & & & 0.209 & 0.50 & 139 & 0.204 & 0.46 & 181 & M \\
\hline & & CS & 7.41 & 1.308 & 0.096 & 0.056 & & & & & 0.184 & 0.08 & 42 & & & & $\mathrm{P}$ \\
\hline \multirow[t]{2}{*}{ NPL } & p-lines & FN & 1.38 & 1.212 & 0.28 & 0.029 & 0.60 & 1.34 & 1.133 & 0.02 & 0.237 & 0.41 & 115 & 0.233 & 0.44 & 137 & $\mathrm{P}$ \\
\hline & & CS & 1.85 & 1.243 & & & & & & & 0.204 & 0.49 & 22 & & & & $\mathrm{P}$ \\
\hline \multirow[t]{2}{*}{ SPL } & s-lines & FN & 2.89 & 1.244 & 0.17 & 0.039 & 0.005 & & & & 0.214 & 0.29 & 50 & 0.216 & 0.47 & 61 & $\mathrm{P}$ \\
\hline & & $\mathrm{CS}$ & 0.62 & 1.831 & 0.48 & 0.098 & & & & & 0.228 & 0.71 & 11 & & & & M \\
\hline \multirow[t]{2}{*}{ WMT } & p-lines & FN & 1.50 & 1.074 & 0.30 & 0.014 & 0.62 & 1.65 & 1.064 & $<0.0001$ & 0.283 & 0.32 & 81 & 0.223 & 0.51 & 566 & $\mathrm{P}$ \\
\hline & & CS & 2.47 & 1.052 & & & & & & & 0.211 & 0.50 & 485 & & & & M \\
\hline \multirow[t]{2}{*}{ XER } & p-lines & FN & 1.51 & 1.104 & 0.29 & 0.018 & 0.48 & 1.27 & 1.078 & 0.002 & 0.258 & 0.51 & 81 & 0.230 & 0.56 & 210 & $P$ \\
\hline & & $\mathrm{CS}$ & 1.91 & 1.093 & & & & & & & 0.211 & 0.59 & 129 & & & & M \\
\hline
\end{tabular}

a Model Type: single - single line fit to combined data for FN and CS streams; p-lines - parallel lines fit; same DHG exponent value ( $\beta$ ) for FN and CS streams, but different coefficient values $(\alpha)$; s-lines - different $\alpha$ and $\beta$ values for FN and CS streams.

b $p$-value for hypothesis that $\beta_{\mathrm{cs}} \neq \beta_{\mathrm{fn}}$ from separate lines model fit.

c First two columns are estimated ratio and its standard error; $p$-value is for test of hypothesis that $\log \alpha_{\mathrm{cs}}-\log \alpha_{\mathrm{fn}}=0$ (or, equivalently, that $\alpha_{\mathrm{cs}} / \alpha_{\mathrm{fn}}=1$ ) in parallel lines model fit.

d Qualitative description of the regression model fit, where fit is classified as good (G) if $r^{2} \geq 0.6$ and RMSE $\leq 0.18$, moderate (M) if $0.5 \leq r^{2}<0.6$ and RMSE $\leq 0.24$, and poor if $r^{2}<0.5$ or RMSE $>0.24$.

ecoregions comprise the group with the lowest $\beta$ values $(0.22$ and 0.23 , respectively); note that regression equations for both of these regions had poor fit (Table 1 ). The four ecoregions comprising the second group (Coastal Plain, Northern Plains, Western Mountains, and Xeric) all had $\beta$ values in the range of 0.28 to 0.31 (Table 1 ). The remaining three ecoregions (Northern and Southern Appalachians and Upper Midwest) had $\beta$ values between 0.37 and 0.39 . None of the differences among ecoregions within these groups were significant $(p>0.05)$, while differences among groups for exponent values pooled within groups were highly significant $(p<0.0001)$, so we fit a parallel lines regression model to test for differences in $\alpha$ among regions within each group (Table 3). (We also combined the Northern and Southern Appalachians into a single region in this model because neither parameter differed significantly between the two regions.) Because $\alpha$ is directly proportional to bankfull width for any fixed drainage area and $\beta$ is constant within groups, the ratio of the $\alpha$ values for any two regions within a group can be interpreted as the ratio of the expected widths in the two regions at any drainage area.

Among regions with similar $\beta$ values, streams in regions with higher precipitation were consistently wider than streams having comparable drainage area in regions with lower precipitation. Among the ecoregions having the lowest $\beta$ value, for example, streams within the Temperate Plains averaged about 1.4 times as wide as streams within the Southern Plains draining the same watershed area (Table 3), reflecting the relative amounts of annual precipitation in the two regions (Fig. 3D). Similarly, among the ecoregions that had the highest $\beta$ value, Appalachian streams were wider by half than streams of the corresponding drainage area in the Upper Midwest, reflecting greater annual precipitation in the Appalachians. The only exception to this pattern was for the Northern Plains and Xeric ecoregions in the group having an intermediate $\beta$ value, where the Northern Plains streams receive slightly more precipitation on average than Xeric streams (Fig. 3D) yet are significantly narrower (Table 3). This is likely the result of nearly ubiquitous flow diversions in this region. Based on data from the EMAP Western Pilot study (Stoddard et al., 2005)which covered most of the Western Mountains, Xeric, and Northern Plains ecoregions $-79 \%$ of sampled sites had one or more upstream dams in the Northern Plains, compared with 11 and 27\% of sites in the Western Mountains and Xeric Ecoregions, respectively. (The abundance of dams in the Northern Plains may also account for the poor fit of the $\mathrm{DHG}_{\mathrm{wA}}$ relationship in this region.) Another factor that may contribute to the difference in width between streams of comparable drainage area in the Northern Plains and the Xeric ecoregions is that the former mostly have dominantly fine bed material while the latter mostly have coarse bed material, an issue we explore in the next section.

\subsubsection{Influence of sediment size on $D H G_{w A}$ relationships}

The width of alluvial channels can be influenced by the caliber of the sediment comprising the bed and banks. For example, canals with cohesive banks in India and the United States were narrower (lower DHG coefficient $\alpha$ ) than those with sandy banks (Simons and Albertson, 1963, reported in Table 5.4 of Knighton, 1998), and various workers have reported DHG equations for gravel-bed streams based on theoretical considerations and empirical data showing that channel width is inversely related to surface $D_{50}$ particle size (Parker, 1979; Ferguson, 1986). We evaluated the influence of particle size on the DHG equations reported in Table 1 using the visually classified particle count data (105 observations per sampled reach) in the EMAP WSA data set (see Faustini and Kaufmann, 2007) as either a continuous or categorical variable in a multiple regression analysis. When incorporated as either a continuous variable or as a categorical variable with five classes (silt/clay, sand, gravel, cobble, boulder), particle size was generally not a significant predictor of channel width. However, classifying streambed substrate as dominantly coarse $(>2 \mathrm{~mm})$ or fine $(<2 \mathrm{~mm})$ based on geometric mean particle size yielded improved predictive models for channel width in several regions. In particular, three of the four WSA ecoregions that were classified as having poor fit in using the simple DHG model (TPL, SPL, and WMT; Table 1) had moderate fit $\left(r^{2} \geq 0.5\right.$ and RMSE $\left.<0.24\right)$ for streams in either the coarse or fine bed material class (Table 4).

Table 4 lists $\mathrm{DHG}_{\mathrm{wA}}$ coefficient and exponent values and model fit statistics for the best fit model for each region from three options: (i) a separate lines model (different coefficient and exponent for fine vs. coarse streams), (ii) a parallel lines model (different coefficient but same exponent for fine and coarse streams), and (iii) a single line model (i.e., the simple linear regression model from Table 1). Fine vs. coarse bed material texture was a significant $(p<0.05)$ explanatory variable in the DHG relationship for bankfull channel width in six of the nine WSA ecoregions (Table 4; Fig. 5). Bed material texture had no significant effect on $\mathrm{DHG}_{\mathrm{wA}}$ relationships in three regions: the Northern Appalachians, Coastal Plain, and Upper Midwest. For these regions, the best fit model was the single line model summarized in Table 1. 
(A) TPL

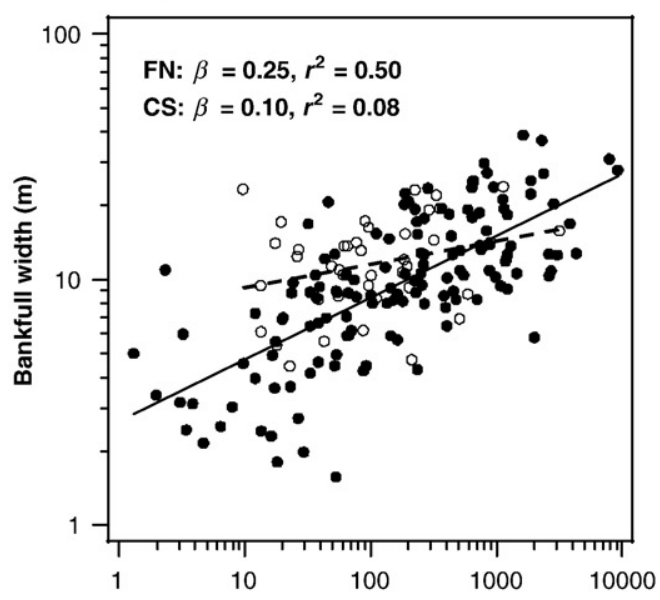

(C) SAP

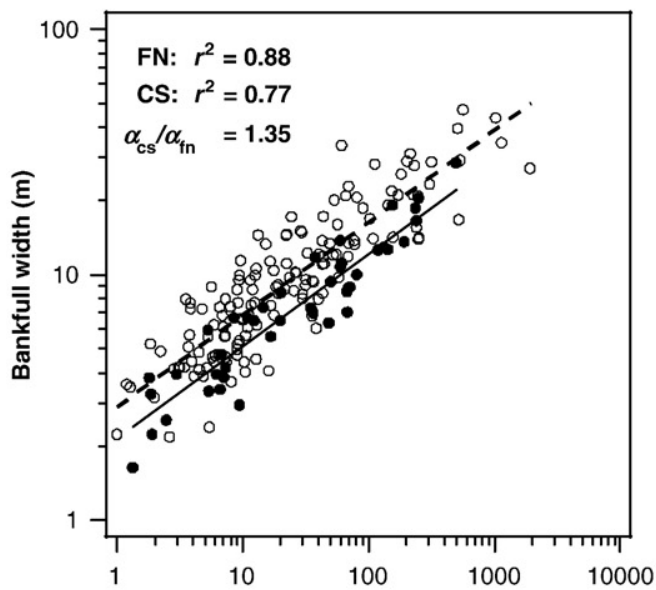

(E) WMT

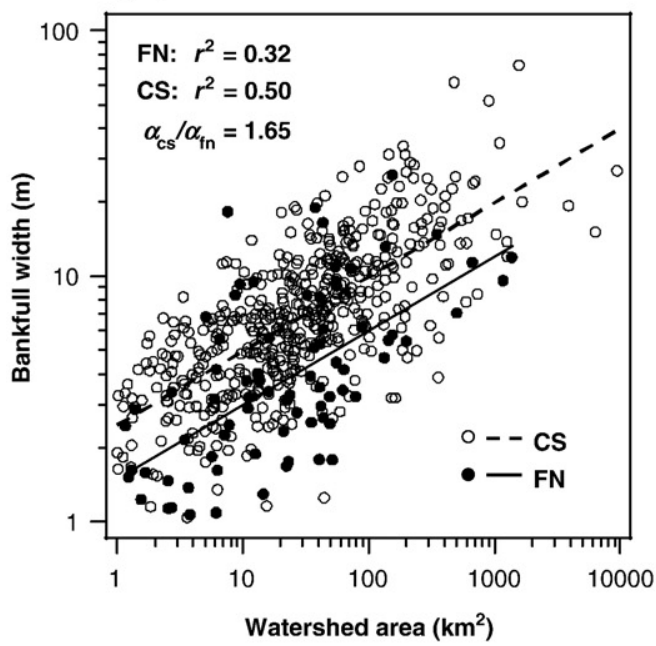

(B) SPL

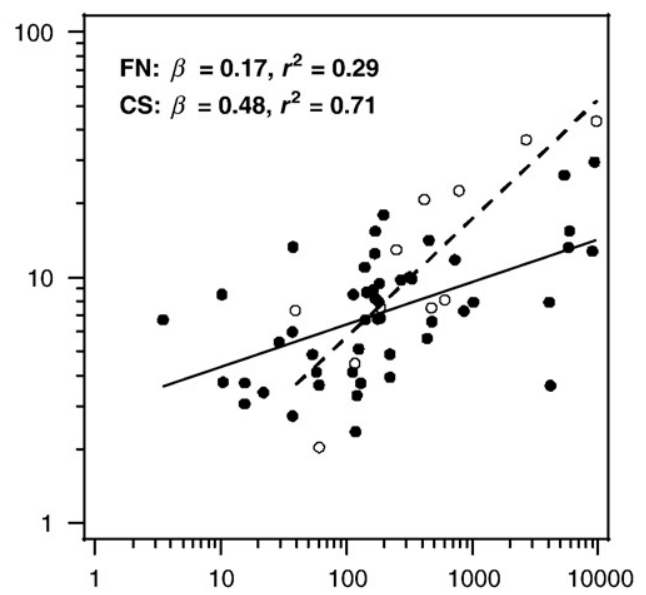

(D) NPL

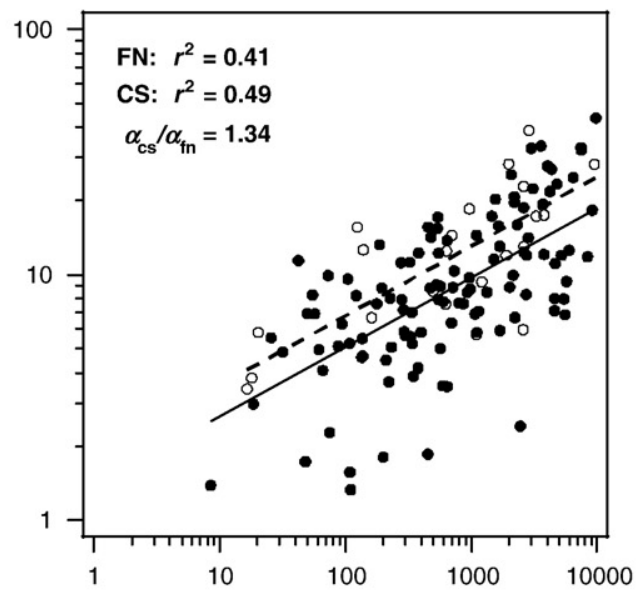

(F) XER

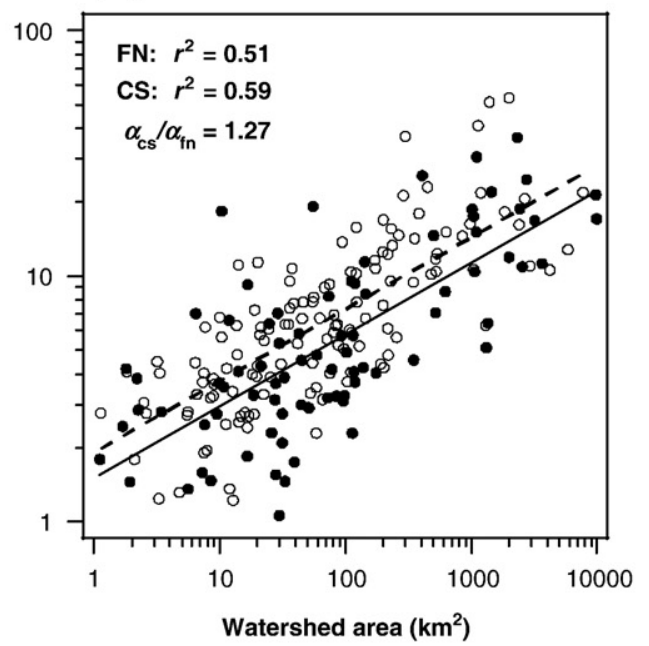

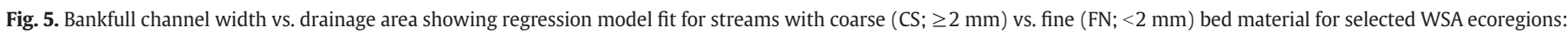

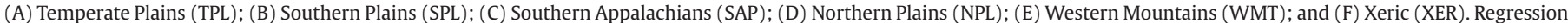
slope parameter (exponent) $\beta$ is constrained to be equal for streams with fine and coarse bed material in panels $\mathrm{C}-\mathrm{F}$ (parallel lines model).

Two regions, the Temperate Plains and the Southern Plains, had significantly different exponent values for fine vs. coarse streams; while there was suggestive but inconclusive evidence $(p=0.06)$ for a difference in exponent values in a third region, the Northern
Appalachians. In the Southern Plains, the exponent value for the 11 coarse streams was 0.48 , nearly three times as great as the value for the 50 fine streams, 0.17. In the Temperate Plains, it was the coarse streams that had a low $\beta$ value (0.096), while fine streams had a 
higher (but still relatively low) $\beta$ value of 0.25 (Table 4 ). In both of these regions, the regression fit for the subset of streams with the smaller $\beta$ value had much lower $r^{2}$ values but also slightly lower RMSE values (indicating better model fit) than the subset with larger $\beta$ values. This indicates that the low $r^{2}$ values for the streams with smaller $\beta$ values are a consequence of those low $\beta$ values (if $\beta=0$, then the regression line is horizontal and $r^{2}$ must necessarily be zero also) rather than a reflection of lower data quality or poorer model fit.

The reason for the difference in $\beta$ values in these two regions may have more to do with the geographic distribution of these sites than with sediment size. In the Temperate Plains, nearly all streams near the southern margin of the Upper Midwest ecoregion (south-central Minnesota, northeastern Iowa, northern Illinois, and southeastern Wisconsin; see Fig. 1) are fine-bedded, and the slope of the width-drainage area relationship is much steeper in this area than in the region as a whole, contributing to the higher $\beta$ value for fine-bedded streams. In the Southern Plains, the slope of the $\mathrm{DHG}_{\mathrm{wA}}$ relationship in south-central Nebraska and west-central Kansas and Oklahoma, where sampled streams are exclusively fine-grained (with one exception) is much lower than the region as a whole. In contrast, it is steeper than the region as a whole in eastern Colorado and central Texas, where all but one of the coarse-bedded streams sampled in the region are located. Thus, the differing geographical distribution of fine and coarse-bedded sites, rather than sediment size itself, may account for the observed difference in the $\mathrm{DHG}_{\mathrm{wA}}$ exponent between fineand coarse-bedded streams in these two regions. This suggests that geographic stratification at a finer spatial scale is needed to develop reliable DHG equations within these regions.

Four of the seven regions for which the exponent value $\beta$ did not differ significantly between fine and coarse streams did exhibit significant differences in the coefficient term (parallel lines model). These were the Southern Appalachians, Northern Plains, Western Mountains, and the Xeric ecoregions (Table 4; Fig. 5). In all four regions, the coefficient was greater for coarse streams than for fine streams, indicating that streams with coarse bed material were wider for a given drainage area than streams with fine bed material. The ratio of coefficient values for coarse vs. fine streams ranged from 1.27 for the Xeric ecoregion to 1.65 for the Western Mountains, indicating that gravel- to boulder-bed streams had mean bankfull widths averaging 27 to $65 \%$ greater than sand- and silt-bed streams with comparable drainage area in these regions.

4.4. $D H G_{w A}$ relationships at smaller spatial scales: Western Mountains ecoregion

As noted previously, using drainage area rather than discharge as the independent variable in hydraulic geometry relationships assumes that a relatively uniform relationship exists between

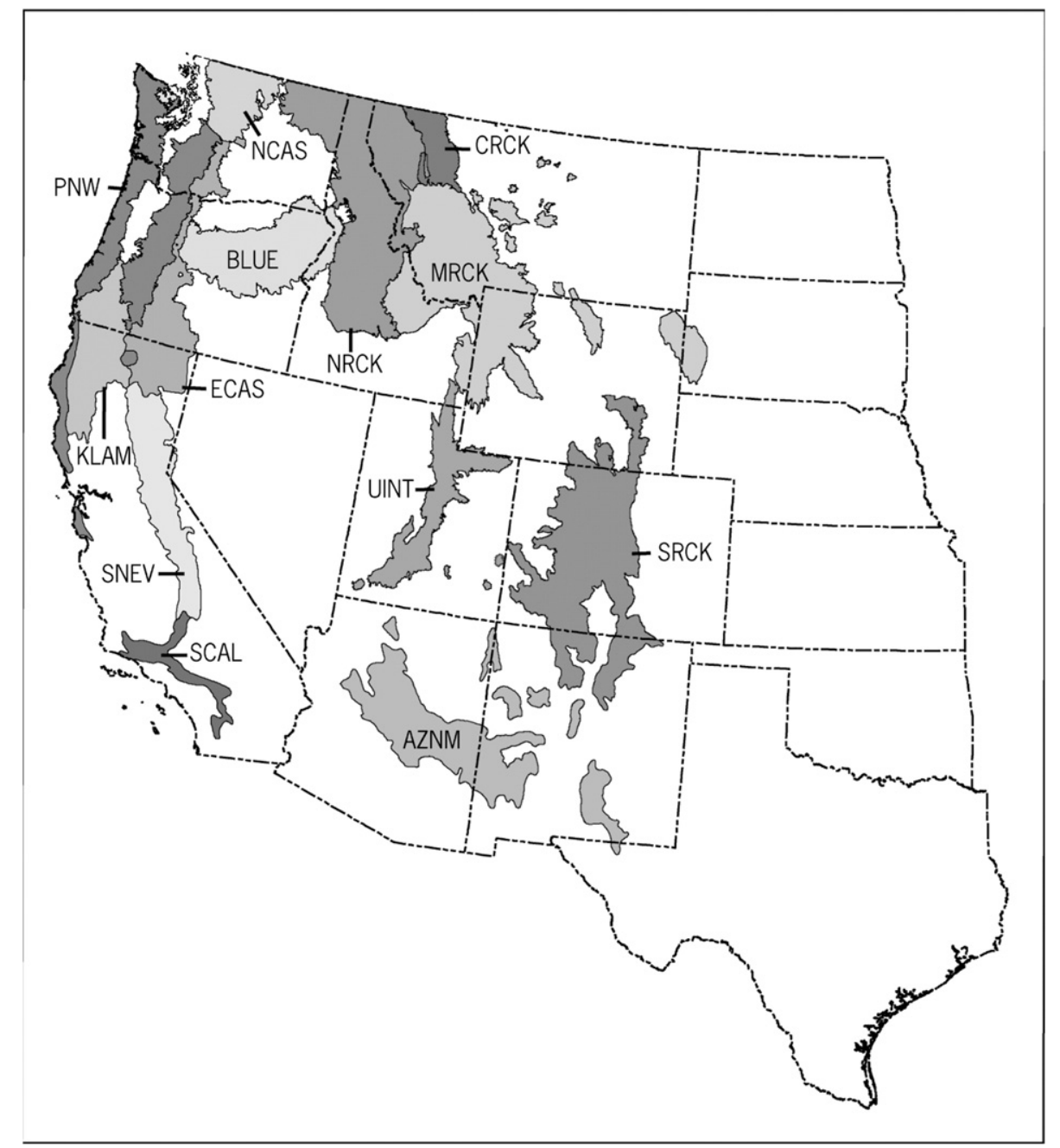

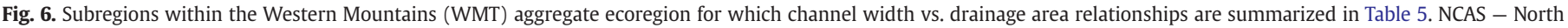

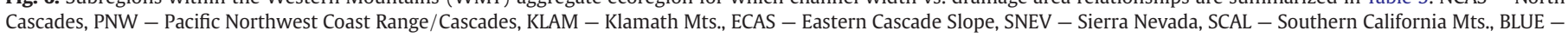

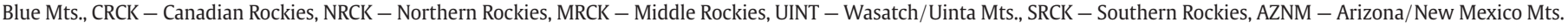


Table 5

DHG equations and fit statistics for bankfull width vs. drainage area by level III ecoregions within the Western Mountains ecoregion ${ }^{\mathrm{a}}$.

\begin{tabular}{|c|c|c|c|c|c|c|c|c|}
\hline Level III ecoregion ${ }^{\mathrm{b}}$ & $\alpha$ & $\mathrm{SE}_{\alpha}^{*}$ & $\beta$ & $\mathrm{SE}_{\beta}$ & RMSE & $r^{2}$ & $n$ & Fit \\
\hline North Cascades ${ }^{\mathrm{c}}$ & 2.59 & 1.19 & 0.38 & 0.052 & 0.23 & 0.59 & 38 & $\mathbf{M}$ \\
\hline Western subregion & 3.49 & 1.10 & 0.36 & 0.028 & 0.11 & 0.87 & 27 & G \\
\hline Eastern subregion & 2.62 & 1.17 & 0.11 & 0.056 & 0.09 & 0.41 & 8 & $P$ \\
\hline Coast Range/Cascades & .05 & 1.12 & 0.36 & 0.035 & 0.15 & 0.69 & 47 & G \\
\hline Klamath Mountains & .43 & 1.13 & 0.34 & 0.038 & 0.15 & 0.65 & 47 & G \\
\hline E. Cascade slope & 1.43 & 1.31 & 0.40 & 0.086 & 0.16 & 0.65 & 14 & G \\
\hline Sierra Nevada & .52 & 1.37 & 0.22 & 0.087 & 0.19 & 0.33 & 15 & $\mathrm{P}$ \\
\hline 2 outliers excluded ${ }^{d}$ & 64 & 1.16 & 0.25 & 0.041 & 0.09 & 0.77 & 13 & G \\
\hline S. California Mts. & 2.17 & 1.19 & 0.24 & 0.046 & 0.17 & 0.45 & 37 & $\mathrm{P}$ \\
\hline Blue Moun & 2.07 & 1.15 & 0.27 & 0.040 & 0.19 & 0.47 & 55 & $\mathrm{P}$ \\
\hline (Silt/sand bed streams) & 1.23 & 1.39 & 0.33 & 0.112 & 0.23 & 0.32 & 21 & $P$ \\
\hline Canadian Rockies & 2.84 & 1.23 & 0.29 & 0.074 & 0.16 & 0.62 & 11 & G \\
\hline Northern Rockies & 2.11 & 1.17 & 0.38 & 0.047 & 0.18 & 0.66 & 36 & G \\
\hline Middle Rockies & 2.16 & 1.15 & 0.33 & 0.038 & 0.20 & 0.54 & 65 & $\mathbf{M}$ \\
\hline & 1.40 & 0.41 & 0.28 & 0.093 & 0.29 & 0.37 & 17 & $P$ \\
\hline Wasatch/Uinta Mts & 3.79 & 1.17 & 0.23 & 0.034 & 0.15 & 0.57 & 37 & G \\
\hline Southern Rockies & 2.12 & 1.22 & 0.27 & 0.058 & 0.23 & 0.36 & 40 & $\mathrm{P}$ \\
\hline AZ/NM Mountains & 2.34 & 1.31 & 0.32 & 0.053 & 0.24 & 0.52 & 35 & M \\
\hline
\end{tabular}

a See Table 1 for explanation of column headings. Data shown are for streams with dominantly coarse (gravel to boulder) bed material except where otherwise indicated (italicized entries). Other than the two regions for which data for silt/sand bed streams are shown, no region had $\geq 10$ sites with predominantly fine bed material.

b Level III ecoregion names (Omernik, 1987). The Coast Range/Cascades region combines the Coast Range and Cascades ecoregions, while the Northern Rockies combines the Northern Rockies and Idaho Batholith ecoregions; all other regions comprise single level III ecoregions.

c The North Cascades can be divided into western and eastern subregions (see Fig. 8). Values for the eastern subregion are for the subset of sites in the Chiwaukum Hills and Lowlands level IV ecoregion (Pater et al., 1998).

${ }^{d}$ Excluding two outlier sites on the periphery of the ecoregion that have anomalously low elevation or mean annual precipitation values (see Fig. 7).

drainage area and the reference discharge (in our case bankfull discharge) over the region of interest. The large spatial extent and topographic and climatic variability incorporated within the Western Mountains and Xeric ecoregions clearly cannot meet this assumption, and presumably this fact contributes to the relatively poor $\mathrm{DHG}_{\mathrm{wA}}$ relationships for these regions (Tables 1 and 3). (In this light, it is interesting to note that of the six water resources regions that, collectively, roughly coincide with the Western Mountains and Xeric ecoregions, only one has a higher $r^{2}$ than the Xeric ecoregion and only two have higher $r^{2}$ values than the Western Mountains ecoregion.) We explore this issue further by examining $\mathrm{DHG}_{\mathrm{wA}}$ relationships at a finer

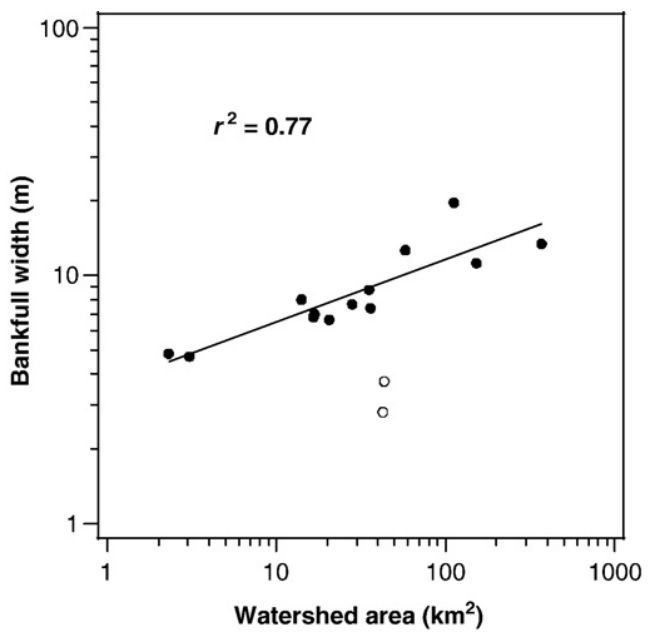

Fig. 7. Plot of bankfull channel width vs. drainage area for the Sierra Nevada Mountains (excluding two streams with fine bed material) showing regression fit; regression parameter values are given in Table 5. Open symbols indicate outliers that were excluded from regression fit (discussed in text). spatial scale, focusing on the Western Mountains ecoregion that covers a geographically discontinuous area, includes large spatial variations in physiography and precipitation, and has a sufficient sample size $(n=566)$ to subdivide into much more compact and presumably more homogenous regions.

We examined DHG relations for bankfull width at the scale of individual level III ecoregions (Omernik, 1987). Two lowland areas (Puget Sound and the Willamette Valley) within the Western Mountains (WMT) WSA ecoregion were excluded and neighboring level III ecoregions were combined in a couple of cases, resulting in 13 analysis regions (Fig. 6). Because the Western Mountains ecoregion has dominantly coarse-bedded streams, we excluded fine-bedded streams from our analysis except for two level III ecoregions (the Blue Mountains and Middle Rockies ecoregions) that included more than 10 fine-bedded streams in the sample. Nine of the 13 analysis regions had good or moderate fit by the previously described criteria, indicating a reasonably well-defined $\mathrm{DHG}_{\mathrm{wA}}$ relationship (Table 5).

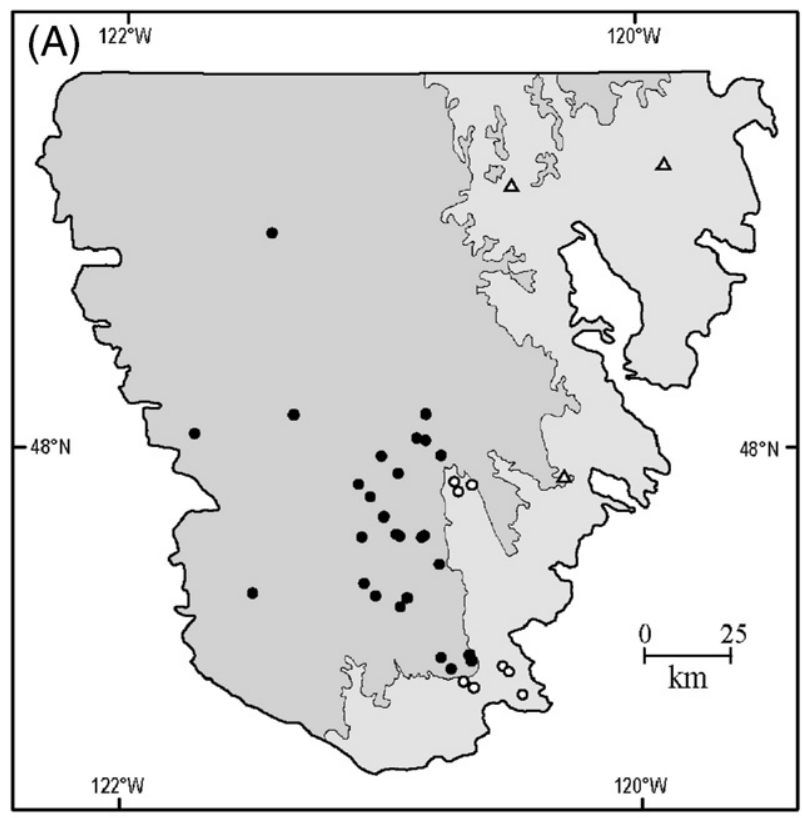

(B)

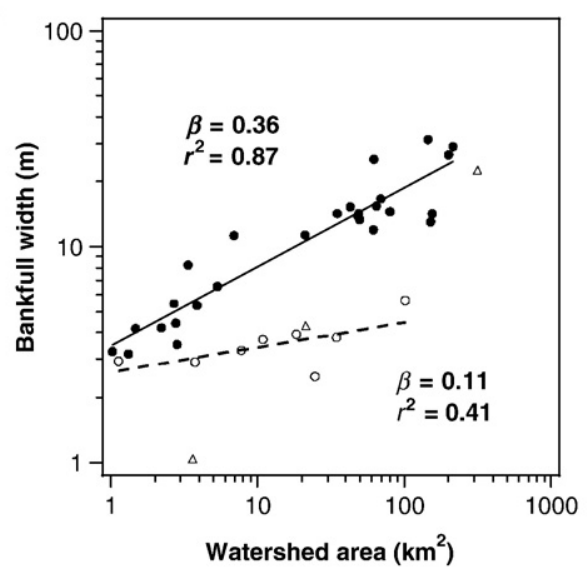

Fig. 8. Map of the North Cascades level III ecoregion (A) showing sampled sites with coarse bed material in western (dark shading, solid symbols) and eastern (light shading, open symbols) subregions, each comprising four level IV ecoregions (Pater et al., 1998). Plot of bankfull channel width vs. drainage area (B) reveals that streams in the western subregion (filled circles, solid line) are wider and increase in width more rapidly with increasing drainage area than those in the Chiwaukum Hills and Lowlands level IV ecoregion in the eastern subregion (open circles, dashed line). The remaining three sites in the eastern subregion (open triangles) are from two different level IV ecoregions and suggest a different trend, but data are too sparse to characterize it. 
A tenth region, the Sierra Nevada, initially exhibited poorly defined DHG, but an examination of the data revealed that this was due to two outliers on the periphery of the ecoregion, one of which was at an anomalously low elevation and the other of which had anomalously low precipitation. When these two sites (out of 15) were removed, the Sierra Nevada had a very strong $\mathrm{DHG}_{\mathrm{wA}}$ relationship (Fig. 7). Thus, only three of 13 level III ecoregions-the Blue Mountains of northeastern Oregon, the Southern California Mountains, and the Southern Rockies-had poorly developed DHG for bankfull channel width.
Although the $\mathrm{DHG}_{\mathrm{wA}}$ relationship for the North Cascades ecoregion had a moderately good fit with an $r^{2}$ of 0.53 , it had a higher RMSE (0.23) than all but two level III ecoregions in the WMT aggregate ecoregion (Table 5). An examination of the width-area scatter plot for this ecoregion reveals two distinct groups of sites that are also geographically distinct (Fig. 8). The $\mathrm{DHG}_{\mathrm{wA}}$ relationship for the western subregion, comprising four level IV ecoregions (Pater et al., 1998), is much better than that for the North Cascades level III ecoregion as a whole $\left(r^{2} 0.87\right.$, RMSE $\left.=0.11\right)$. In the eastern subregion

Table 6

Multiple linear regression results: predictive models for bankfull width (log $w$ ) by WSA ecoregions excluding most-disturbed sites.

\begin{tabular}{|c|c|c|c|c|c|c|c|c|}
\hline Region & Base model $^{\mathrm{a}}$ & Variable $^{\mathrm{b}}$ & Estimate & SE & $p$-value & RMSE $^{\mathrm{c}}$ & $r^{2}$ & $n$ \\
\hline \multirow[t]{4}{*}{ N. APPALACHIANS (NAP) } & \multirow[t]{4}{*}{ single } & Int & 0.1195 & 0.1178 & 0.3138 & \multirow[t]{2}{*}{0.1421} & \multirow[t]{2}{*}{0.733} & \multirow[t]{4}{*}{69} \\
\hline & & $\log A$ & 0.3702 & 0.0321 & $<0.0001$ & & & \\
\hline & & $\log P_{\text {fn }}$ & -2.6518 & 0.8468 & 0.0026 & 0.1392 & 0.748 & \\
\hline & & $\log S$ & -0.1895 & 0.0729 & 0.0115 & 0.1335 & 0.771 & \\
\hline \multirow[t]{4}{*}{ S. APPALACHIANS (SAP) } & \multirow[t]{4}{*}{ p-lines } & $I n t_{\mathrm{fn}}$ & 0.3058 & 0.0375 & $<0.0001$ & \multirow[t]{3}{*}{0.1297} & \multirow[t]{3}{*}{0.804} & \multirow[t]{4}{*}{130} \\
\hline & & $\operatorname{Int}_{\mathrm{cs}}$ & 0.6053 & 0.0677 & $<0.0001$ & & & \\
\hline & & $\log A$ & 0.3935 & 0.0174 & $<0.0001$ & & & \\
\hline & & $\log S_{\mathrm{cs}}$ & 0.0852 & 0.0351 & 0.0165 & 0.1273 & 0.812 & \\
\hline \multirow[t]{4}{*}{ COASTAL PLAIN (CPL) } & \multirow[t]{4}{*}{ single } & $I n t_{\mathrm{fn}}$ & 0.4332 & 0.0428 & $<0.0001$ & \multirow[t]{3}{*}{0.1644} & \multirow[t]{3}{*}{0.579} & \multirow[t]{4}{*}{69} \\
\hline & & $\operatorname{Int}_{\mathrm{cs}}$ & 0.8927 & 0.1150 & $<0.0001$ & & & \\
\hline & & $\log A$ & 0.2604 & 0.0280 & $<0.0001$ & & & \\
\hline & & $Z_{\mathrm{cs}}$ & -0.00557 & 0.0013 & $<0.0001$ & 0.1449 & 0.683 & \\
\hline \multirow[t]{5}{*}{ UPPER MIDWEST (UMW) } & \multirow[t]{5}{*}{ single } & Int & 0.2536 & 0.0630 & 0.0002 & \multirow[t]{2}{*}{0.1599} & \multirow[t]{2}{*}{0.729} & \multirow[t]{5}{*}{47} \\
\hline & & $\log A$ & 0.4110 & 0.0316 & $<0.0001$ & & & \\
\hline & & $\log P_{\mathrm{fn}}$ & 2.5732 & 0.7640 & 0.0013 & 0.1575 & 0.743 & \\
\hline & & $Z_{\mathrm{fn}}$ & 0.00137 & 0.00029 & $<0.0001$ & 0.1366 & 0.811 & \\
\hline & & $\log S_{\mathrm{fn}}$ & 0.0876 & 0.0364 & 0.0206 & 0.1296 & 0.834 & \\
\hline \multirow[t]{6}{*}{ TEMPERATE PLAINS (TPL) } & \multirow[t]{6}{*}{ s-lines } & $I n t_{\mathrm{fn}}$ & 0.3957 & 0.0494 & $<0.0001$ & \multirow[t]{4}{*}{0.1877} & 0.452 & 126 \\
\hline & & Int $_{\mathrm{cs}}$ & 0.8318 & 0.1075 & $<0.0001$ & & & \\
\hline & & $\log A_{\mathrm{fn}}$ & 0.3498 & 0.0247 & $<0.0001$ & & & \\
\hline & & $\log A_{\mathrm{cs}}$ & 0.1516 & 0.0576 & 0.0096 & & & \\
\hline & & $\log P_{\text {fn }}$ & 1.1730 & 0.1506 & $<0.0001$ & 0.1545 & 0.632 & \\
\hline & & $\log P_{\mathrm{cs}}$ & 0.5172 & 0.2478 & 0.0390 & 0.1524 & 0.645 & \\
\hline NORTHERN PLAINS (NPL) & p-lines & $I n t_{\mathrm{fn}}$ & 0.4041 & 0.1303 & 0.0026 & 0.2106 & 0.552 & 97 \\
\hline & & $\operatorname{Int}_{\mathrm{cs}}$ & 0.2607 & 0.0935 & 0.0064 & & & \\
\hline & & $\log A$ & 0.2788 & 0.0296 & $<0.0001$ & & & \\
\hline & & $Z_{\mathrm{fn}}$ & -0.00034 & 0.00010 & 0.0006 & 0.1987 & 0.605 & \\
\hline SOUTHERN PLAINS (SPL) & s-lines & $I_{\mathrm{fn}}$ & 0.7568 & 0.1712 & $<0.0001$ & 0.2278 & 0.454 & 48 \\
\hline & & Int $\mathrm{cs}_{\mathrm{cs}}$ & 0.2851 & 0.3032 & 0.3524 & & & \\
\hline & & $\log A_{\mathrm{fn}}$ & 0.1666 & 0.0480 & 0.0012 & & & \\
\hline & & $\log A_{\mathrm{cs}}$ & 0.4920 & 0.0954 & $<0.0001$ & & & \\
\hline & & $Z_{\mathrm{cs}}$ & -0.00024 & 0.00009 & 0.0124 & 0.2170 & 0.516 & \\
\hline & & $\log S$ & 0.1296 & 0.0644 & 0.0508 & 0.2097 & 0.558 & \\
\hline WESTERN MOUNTAINS (WMT) & p-lines & $I n t_{\mathrm{fn}}$ & 0.1825 & 0.0313 & $<0.0001$ & 0.2106 & 0.509 & 490 \\
\hline & & $\operatorname{Int}_{\mathrm{cs}}$ & 0.2524 & 0.0284 & $<0.0001$ & & & \\
\hline & & $\log A$ & 0.3986 & 0.0137 & $<0.0001$ & & & \\
\hline & & $\log P$ & 0.6167 & 0.0428 & $<0.0001$ & 0.1760 & 0.658 & \\
\hline & & $Z_{\mathrm{cs}}$ & 0.000033 & 0.000011 & 0.0046 & 0.1747 & 0.664 & \\
\hline XERIC (XER) & p-lines & $I t_{\mathrm{fn}}$ & 0.1168 & 0.0515 & 0.0248 & 0.2215 & 0.555 & 165 \\
\hline & & $\operatorname{Int}_{\mathrm{cs}}$ & 0.3383 & 0.0550 & $<0.0001$ & & & \\
\hline & & $\log A$ & 0.3223 & 0.0222 & $<0.0001$ & & & \\
\hline & & $\log P_{\mathrm{cs}}$ & 0.3048 & 0.1208 & 0.0126 & 0.2180 & 0.572 & \\
\hline
\end{tabular}

a Base model (italicized rows) is best-fit model including only drainage area and bed material type (same model as in Table 4 refitted to data after excluding most-disturbed sites):

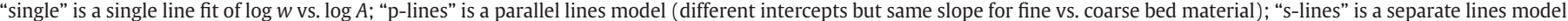
(different slope and intercept for fine vs. coarse bed material).

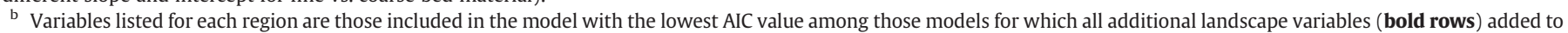

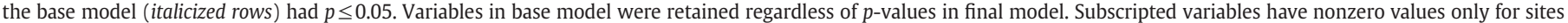

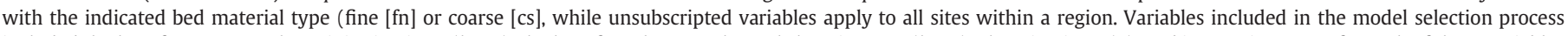

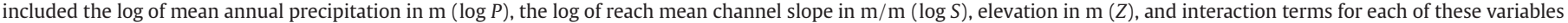
with an indicator variable for bed material type. Indicated $p$-values are for the hypothesis that the parameter value is zero based on type III sum of squares.

c The final three columns list the root mean square error, coefficient of determination, and number of observations used in the base model (Int and log $A$ terms) and in models with additional landscape variables added ( $\log P, \log S$ and $Z$ terms) assuming all preceding terms listed (but not any subsequently listed terms) are included in the model. 
(A) NAP

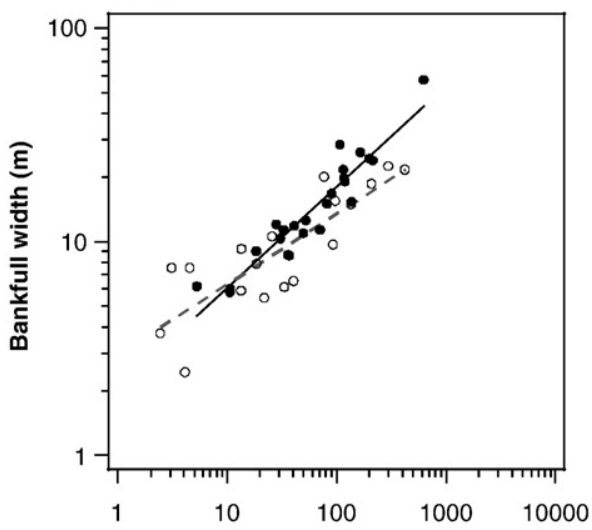

(D) UMW

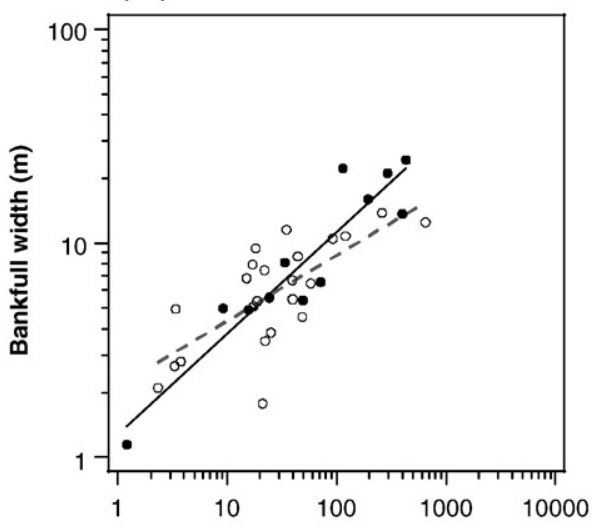

(G) SPL

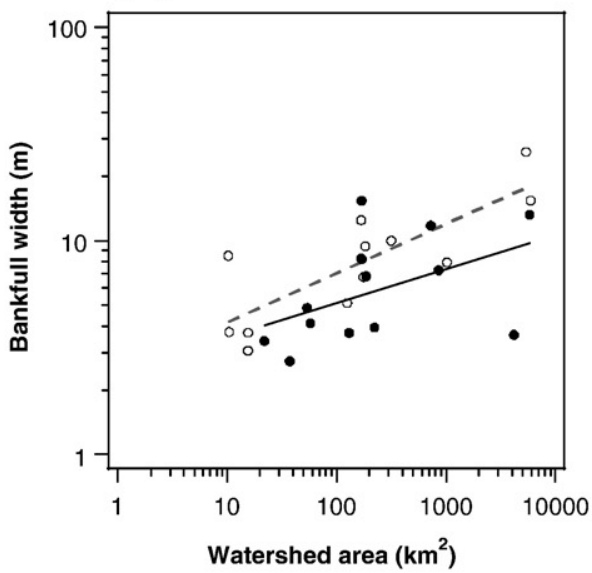

(B) SAP

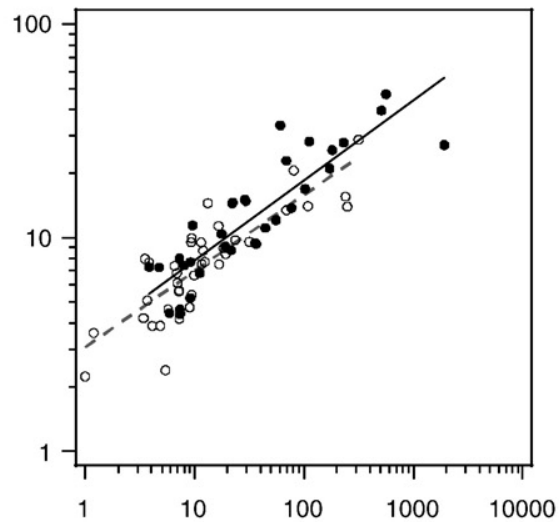

(E) TPL

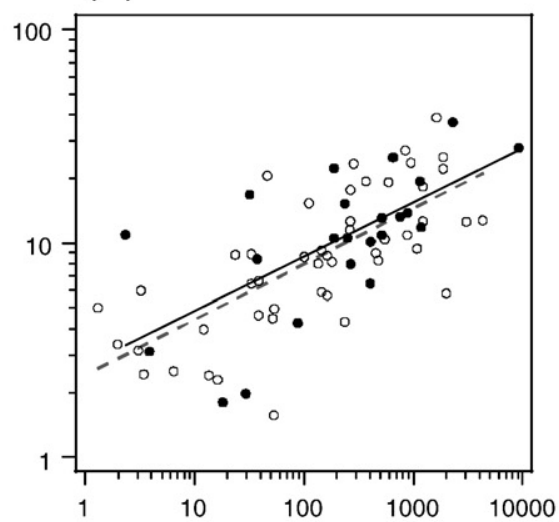

(H) WMT

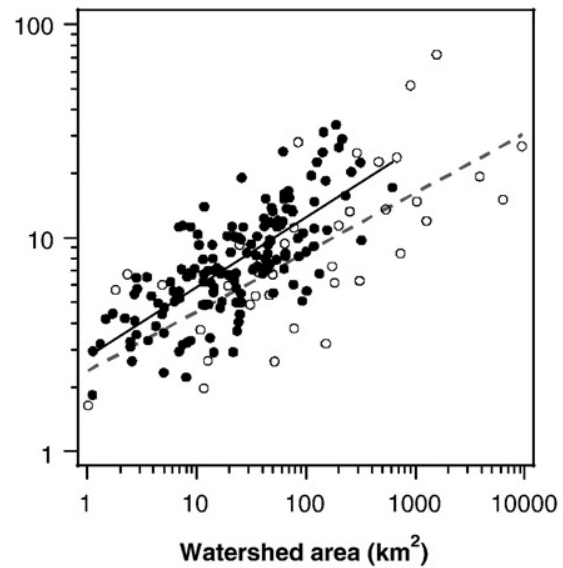

(C) $\mathrm{CPL}$

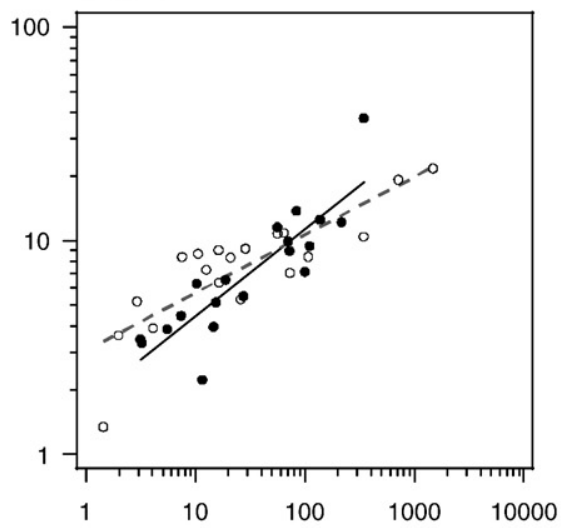

(F) NPL

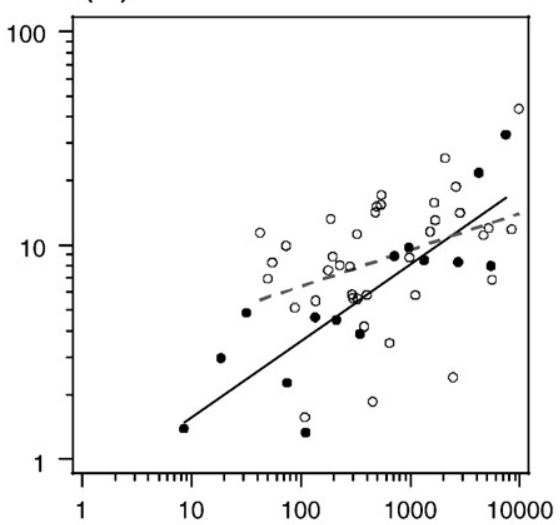

(I) XER

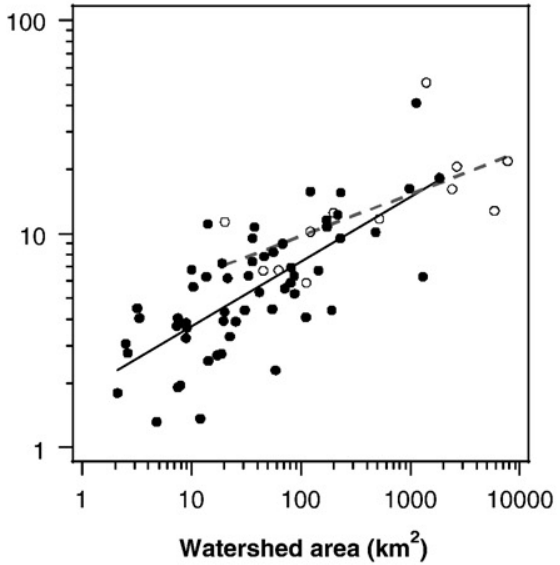

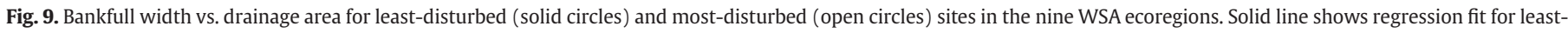
disturbed sites, dashed line for most-disturbed sites. Regression equations and fit statistics are given in Table 7.

(also comprising four level IV ecoregions), 8 of the 11 sites (open circles in Fig. 8) are located within a single level IV ecoregion, the Chiwaukum Hills and Lowlands. This area is underlain by highly erodible sandstone with high sediment yields (Pater et al., 1998). Relative to the western subregion, sampled channels in the Chiwaukum Hills and Lowlands were much narrower and increased in width much more slowly with drainage area $\left(\beta=0.11, r^{2}=0.41\right)$. (Note that the low $r^{2}$ value in this case is due to the low slope of the $\mathrm{DHG}_{\mathrm{wA}}$ relationship, which has a low RMSE of 0.09.) This pattern reflects the lower precipitation in the Chiwaukum Hills and Lowlands (median $=857 \mathrm{~mm}$ vs. $1630 \mathrm{~mm}$ for sites in the western subregion) and a very strong negative correlation between mean annual precipitation and drainage area $(r=-0.97$ with both variables logtransformed), which suggests that discharge increases slowly with increasing drainage area in the Chiwaukum Hills and Lowlands. The remaining three sites in the eastern subregion (open triangles in Fig. 8), located within two other level IV ecoregions to the north and east, do not appear to fit the trend of sites in either the Chiwaukum Hills and Lowlands or the western subregion, but there are insufficient data to define a $\mathrm{DHG}_{w A}$ relationship.

In summary, we found evidence of well-developed $\mathrm{DHG}_{\mathrm{wA}}$ relationships in 10 of 13 subdivisions of the Western Mountains 
Table 7

Anthropogenic impacts on DHG: equations and fit statistics for bankfull width vs. drainage area by WSA ecoregions for least- vs. most-disturbed sites, separate lines model ${ }^{\mathrm{a}}$.

\begin{tabular}{|c|c|c|c|c|c|c|c|c|c|c|c|}
\hline Region & Bed material & Disturb. level & $\alpha$ & $\mathrm{SE}_{\alpha}^{*}$ & $\beta$ & $S E_{\beta}$ & $p$ for $\Delta \beta$ & RMSE & $r^{2}$ & $n$ & Model fit \\
\hline \multirow[t]{2}{*}{ N. APPALACHIANS (NAP) } & $\mathrm{FN}+\mathrm{CS}$ & Low & 2.02 & 1.24 & 0.48 & 0.052 & 0.035 & 0.084 & 0.88 & 24 & $\mathrm{G}$ \\
\hline & & High & 2.95 & 1.17 & 0.33 & 0.053 & & 0.154 & 0.70 & 18 & G \\
\hline \multirow[t]{2}{*}{ S. APPALACHIANS (SAP) } & CS & Low & 3.31 & 1.15 & 0.37 & 0.037 & 0.74 & 0.140 & 0.77 & 32 & G \\
\hline & & High & 3.08 & 1.12 & 0.36 & 0.039 & & 0.134 & 0.70 & 39 & G \\
\hline \multirow[t]{2}{*}{ COASTAL PLAIN (CPL) } & $\mathrm{FN}+\mathrm{CS}$ & Low & 1.75 & 1.23 & 0.41 & 0.056 & 0.059 & 0.143 & 0.77 & 19 & G \\
\hline & & High & 3.06 & 1.17 & 0.27 & 0.042 & & 0.148 & 0.71 & 19 & G \\
\hline \multirow[t]{2}{*}{ UPPER MIDWEST (UMW) } & $\mathrm{FN}+\mathrm{CS}$ & Low & 1.27 & 1.34 & 0.47 & 0.067 & 0.072 & 0.144 & 0.87 & 12 & G \\
\hline & & High & 2.15 & 1.24 & 0.31 & 0.061 & & 0.178 & 0.52 & 23 & M \\
\hline \multirow[t]{2}{*}{ TEMPERATE PLAINS (TPL) } & FN & Low & 2.70 & 1.41 & 0.25 & 0.060 & 0.93 & 0.265 & 0.42 & 23 & $\mathrm{P}$ \\
\hline & & High & 2.42 & 1.23 & 0.26 & 0.039 & & 0.235 & 0.50 & 49 & M \\
\hline \multirow[t]{2}{*}{ NORTHERN PLAINS (NPL) } & FN & Low & 0.69 & 1.60 & 0.36 & 0.076 & 0.072 & 0.218 & 0.71 & 15 & M \\
\hline & & High & 2.91 & 1.55 & 0.17 & 0.067 & & 0.276 & 0.14 & 38 & $P$ \\
\hline \multirow[t]{2}{*}{ SOUTHERN PLAINS (SPL) } & FN & Low & 2.47 & 1.55 & 0.16 & 0.076 & 0.47 & 0.228 & 0.23 & 13 & $\mathrm{P}$ \\
\hline & & High & 2.44 & 1.39 & 0.23 & 0.061 & & 0.160 & 0.66 & 13 & G \\
\hline \multirow[t]{2}{*}{ WESTERN MOUNTAINS (WMT) } & CS & Low & 2.75 & 1.10 & 0.33 & 0.028 & 0.25 & 0.170 & 0.55 & 151 & M \\
\hline & & High & 2.38 & 1.19 & 0.28 & 0.033 & & 0.267 & 0.50 & 38 & $\mathrm{P}$ \\
\hline \multirow[t]{2}{*}{ XERIC (XER) } & CS & Low & 1.84 & 1.17 & 0.30 & 0.039 & 0.19 & 0.205 & 0.52 & 57 & M \\
\hline & & High & 3.96 & 1.56 & 0.20 & 0.070 & & 0.206 & 0.44 & 12 & $\mathrm{P}$ \\
\hline
\end{tabular}

a See Table 4 for explanation of column headings; $p$-values in this table (boldface where $p \leq 0.05$ ) are for parameter differences between least- and most-disturbed sites. All

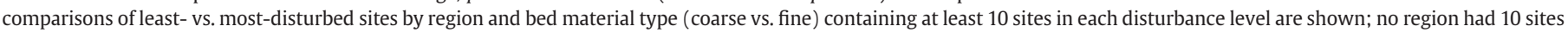

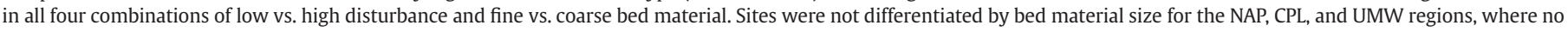
significant difference in regression parameters by bed material size was found (see text and Table 4).

aggregated ecoregion at the scale of level III ecoregions, with $r^{2}$ values ranging from 0.52 to 0.77 ( 0.87 counting the western subregion of the North Cascades) and $\beta$ values ranging from 0.23 to 0.40 . Internal heterogeneity in climate, geology, or other factors, leading to differing $\mathrm{DHG}_{\mathrm{wA}}$ relationships within a single level III ecoregion as we found in the North Cascades of western Washington, may account for the absence of well-defined $\mathrm{DHG}_{\mathrm{wA}}$ relationships in some level III ecoregions.

\subsection{Multivariate predictive models for bankfull channel width}

As described in Section 3.2.3, we developed region-specific MLR models to predict channel width for sites with low to moderate anthropogenic disturbance using log-transformed values of mean annual precipitation $(P)$, reach-average channel gradient $(S)$, and site elevation $(Z)$ in addition to drainage area and sediment size. The resulting predictive models had four to six parameters (including intercepts) and $r^{2}$ values ranging from 0.56 for the Southern Plains to
0.83 for the Upper Midwest (Table 6). Relative to the DHG equations in Table 4 refit after excluding the most-disturbed sites ("base model" in Table 6), the added landscape variables explained an additional $10-19 \%$ of variance in bankfull channel width in five of the nine WSA ecoregions (CPL, UMW, TPL, SPL, and WMT), with smaller increases in $r^{2}$ in the remaining regions (Table 6). Precipitation and elevation were each significant explanatory variables in five regions, while channel gradient was included in the predictive models for four regions. In most cases, these additional explanatory variables had effects that were nonzero for just one category of streams (coarse or fine) or that differed for fine- vs. coarse-bedded streams (Table 6).

The addition of precipitation as an explanatory variable substantially improved model fit for the Temperate Plains and Western Mountains ecoregions, increasing $r^{2}$ from 0.45 to 0.65 in the former and from 0.51 to 0.66 in the latter. Increases in the coefficient of determination associated with precipitation were much smaller for the other regions, on the order of 0.02 or less. For the Temperate

Table 8

Summary of regression results for log-transformed values of bankfull width vs. drainage area by WSA ecoregions for least- vs. most-disturbed sites, parallel lines model ${ }^{\mathrm{a}}$.

\begin{tabular}{|c|c|c|c|c|c|c|c|c|c|c|c|c|c|}
\hline Region & Bed material & Disturb. level & $\alpha$ & $\mathrm{SE}_{\alpha}^{*}$ & $\beta$ & $\mathrm{SE}_{\beta}$ & RMSE & $r^{2}$ & $n$ & $\alpha_{\mathrm{H}} / \alpha_{\mathrm{L}}$ & $\mathrm{SE}^{*} \alpha_{\mathrm{H}} / \alpha_{\mathrm{L}}$ & $p$-value for $\alpha_{\mathrm{H}} / \alpha_{\mathrm{L}}$ & Model fit \\
\hline \multirow[t]{2}{*}{ N. APPALACHIANS (NAP) } & $\mathrm{FN}+\mathrm{CS}$ & Low & 2.90 & 1.18 & 0.39 & 0.034 & 0.092 & 0.85 & 24 & 0.84 & 1.10 & 0.056 & $\bar{G}$ \\
\hline & & High & 2.42 & 1.16 & & & 0.154 & 0.68 & 18 & & & & G \\
\hline \multirow[t]{2}{*}{ S. APPALACHIANS (SAP) } & CS & Low & 3.41 & 1.12 & 0.37 & 0.027 & 0.137 & 0.77 & 32 & 0.88 & 1.08 & 0.11 & G \\
\hline & & High & 3.01 & 1.09 & & & 0.126 & 0.70 & 39 & & & & G \\
\hline \multirow[t]{2}{*}{ COASTAL PLAIN (CPL) } & $\mathrm{FN}+\mathrm{CS}$ & Low & 2.35 & 1.15 & 0.32 & 0.035 & 0.15 & 0.73 & 19 & 1.11 & 1.12 & 0.36 & G \\
\hline & & High & 2.61 & 1.15 & & & 0.15 & 0.69 & 19 & & & & G \\
\hline \multirow[t]{2}{*}{ UPPER MIDWEST (UMW) } & $\mathrm{FN}+\mathrm{CS}$ & Low & 1.83 & 1.25 & 0.38 & 0.047 & 0.15 & 0.84 & 12 & 0.92 & 1.16 & 0.55 & G \\
\hline & & High & 1.67 & 1.19 & & & 0.18 & 0.49 & 23 & & & & $\mathrm{P}$ \\
\hline \multirow[t]{2}{*}{ TEMPERATE PLAINS (TPL) } & FN & Low & 2.64 & 1.23 & 0.26 & 0.033 & 0.26 & 0.42 & 23 & 0.93 & 1.15 & 0.59 & $\mathrm{P}$ \\
\hline & & High & 2.44 & 1.20 & & & 0.23 & 0.50 & 49 & & & & M \\
\hline \multirow[t]{2}{*}{ NORTHERN PLAINS (NPL) } & FN & Low & 1.27 & 1.41 & 0.25 & 0.052 & 0.23 & 0.65 & 15 & 1.36 & 1.21 & 0.11 & M \\
\hline & & High & 1.73 & 1.41 & & & 0.28 & 0.11 & 38 & & & & $\mathrm{P}$ \\
\hline \multirow[t]{2}{*}{ SOUTHERN PLAINS (SPL) } & FN & Low & 1.95 & 1.33 & 0.20 & 0.047 & 0.22 & 0.21 & 13 & 1.45 & 1.19 & 0.049 & $P$ \\
\hline & & High & 2.81 & 1.31 & & & 0.16 & 0.65 & 13 & & & & G \\
\hline \multirow[t]{2}{*}{ WESTERN MOUNTAINS (WMT) } & CS & Low & 2.93 & 1.08 & 0.31 & 0.021 & 0.17 & 0.55 & 151 & 0.71 & 1.09 & 0.0001 & M \\
\hline & & High & 2.07 & 1.13 & & & 0.27 & 0.50 & 38 & & & & $\mathrm{P}$ \\
\hline \multirow[t]{2}{*}{ XERIC (XER) } & CS & Low & 2.02 & 1.15 & 0.28 & 0.034 & 0.20 & 0.52 & 57 & 1.2 & 1.19 & 0.29 & M \\
\hline & & High & 2.42 & 1.28 & & & 0.21 & 0.36 & 12 & & & & $\mathrm{P}$ \\
\hline
\end{tabular}

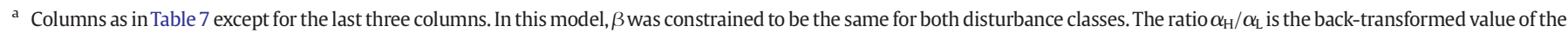

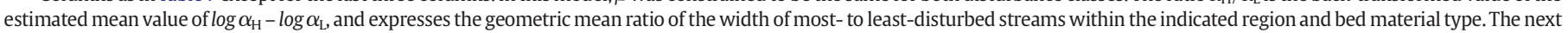
column shows the multiplicative standard error for this estimate, and the final column gives the associated $p$-value (boldface for $p \leq 0.05)$ from $t$-test. 
Plains, the regression coefficient value for $\log P$ was much greater for fine-bedded than coarse-bedded streams, 1.17 vs. 0.52 . These values translate to an increase in width of $125 \%$ and $43 \%$, respectively, for a doubling of precipitation. (For the Temperate Plains, estimated mean annual precipitation at sampled sites ranged from about 400 to $1200 \mathrm{~mm}$, a threefold range.) In the Western Mountains, where the among-site range in mean annual precipitation is greatest ( 200 to $3700 \mathrm{~mm}$; Fig. 3D), the coefficient of $\log P$ was 0.62 for fine- and coarse-bedded streams combined, equivalent to an $~ 50 \%$ increase in channel width with each doubling of precipitation.

After precipitation, elevation above mean sea level, $Z$ (the only explanatory variable not log-transformed in our analysis), contributed the most to improving model predictions. As noted earlier, within an ecoregion and in combination with drainage area, elevation is generally a proxy for site location on a headwaters-to-mouth continuum, though it might also serve to differentiate streams with snowmelt-dominated vs. rainfall-dominated hydrographs. Inclusion of elevation increased $r^{2}$ by between 0.05 and 0.10 for four regions (CPL, UMW, NPL, and SPL) and by 0.006 for the Western Mountains, where it was still statistically significant because of the large number of sites (Table 6). Among the landscape variables, channel slope had the least impact on predicted bankfull channel width. Log $S$ was significant in the models for four regions (NAP, SAP, UMW, and SPL), but it was the least significant variable in each case and only increased the model $r^{2}$ by approximately 0.01 to 0.04 .

\subsection{Anthropogenic effects}

\subsubsection{DHG for least-disturbed vs. most-disturbed sites}

To assess the potential influence of anthropogenic disturbance on DHG, we first compared the basic $\mathrm{DHG}_{\mathrm{wA}}$ relationships (i.e., Table 4, not the more complex multivariate models in Table 6) for the low and high disturbance classes, excluding sites with intermediate disturbance, to test whether $\mathrm{DHG}_{\mathrm{wA}}$ relationships differed for leastvs. most-disturbed sites (Fig. 9; Table 7). For regions in which there was no significant difference between the DHG exponent and coefficient values for streams with fine vs. coarse bed material (NAP, CPL, and UMW; see Table 4), we included both fine- and coarse-bedded streams in the analysis, while for the remaining regions we included only streams with the dominant substrate type in the region (i.e., fine for the plains ecoregions and coarse for the mountain ecoregions).

There was negligible difference between the least- and mostdisturbed sites in two regions (SAP and TPL), while in two other regions the most-disturbed sites were generally wider (SPL) or narrower (WMT) than the least-disturbed sites (Fig. 9). The slope of the $\mathrm{DHG}_{\mathrm{wA}}$ relationship did not differ significantly between least- and most-disturbed sites in either of the latter regions (i.e., the $\beta$ values were not significantly different, Table 7 ); but when a parallel lines model was fit to the data, the intercepts (i.e., the $\alpha$ values) did differ significantly (Table 8). In the remaining five regions (NAP, CPL, UMW, $\mathrm{NPL}$, and XER), $\beta$ values were consistently lower for the mostdisturbed sites than for the least-disturbed sites, as can be seen in the lower slope of the $\mathrm{DHG}_{\mathrm{wA}}$ curves for the most-disturbed sites (dashed lines) in Fig. 9. The differences are not necessarily statistically significant ( $p$-values of 0.19 for XER and $0.04-0.07$ for the other regions; see Table 7 ), but they are strikingly consistent in sign and relatively large in magnitude ( $\beta$ values were lower by 0.10 to 0.19 , or $\sim 30$ to 50\%, among most-disturbed sites). These differences are fairly large relative to the range of values reported in the literature (Table 2), and it is likely that larger sample sizes would have yielded higher levels of statistical significance. (All four regions had $<20$ sites in either the low or high disturbance classes; Table 7.) The lower $\beta$ values for disturbed streams may, at least in part, account for the somewhat lower $\beta$ values we generally found when including all streams (Table 1 ) relative to values reported by others (Table 2 ).
What could explain the pattern of lower $\beta$ values at higher levels of disturbance observed within these five regions? Disturbances such as flow diversions, groundwater pumping, channelization, removal of woody debris and riparian vegetation, and bank armoring could potentially contribute to reduced channel width by reducing runoff, reducing channel roughness (hence increasing conveyance capacity for a given channel cross section), and constraining the channel's ability to widen through bank erosion. (Note that riparian vegetation removal could have the opposite effect of increasing channel width if it destabilizes streambanks.) To the extent that these types of disturbances typically increase in the downstream direction, the overall effect is likely to be to decrease $\beta$. Conversely, disturbances such as logging or land clearing, roads, urban development, cattle grazing, and removal of riparian vegetation could contribute to increased channel width by increasing runoff, increasing sediment yield (potentially leading to channel aggradation), and decreasing bank strength. To the extent that these types of disturbance disproportionately affect smaller catchments because of where they occur on the landscape (e.g., logging) or because the magnitude of impact is greater in smaller catchments (e.g., urbanization), the overall effect will likewise be in the direction of decreasing $\beta$.

Not surprisingly, DHG relationships were generally stronger among sites with lower levels of anthropogenic disturbance. In seven of the nine WSA regions, excluding only the Temperate Plains and Southern Plains ecoregions, the $\mathrm{DHG}_{\mathrm{wA}}$ relationship was stronger (higher $r^{2}$ and generally lower RMSE) for least-disturbed sites than for most-disturbed sites-most dramatically in the Northern Appalachians, Upper Midwest, and Northern Plains ecoregions (Table 7). A notable exception was the Southern Plains, which for an unknown reason exhibited a much stronger $\mathrm{DHG}_{\mathrm{wA}}$ relationship among the most-disturbed sites $\left(r^{2}=0.66\right)$ than the least-disturbed sites $\left(r^{2}=0.23\right)$.

A test of $\mathrm{DHG}_{\mathrm{wA}}$ coefficient values in a parallel lines regression model provided strong evidence that bankfull width for streams of comparable drainage area differed between least-disturbed and mostdisturbed sites in the Western Mountains $(p<0.0001)$ and moderate evidence for the Southern Plains ( $p=0.05$; Table 8$)$. There was slightly weaker evidence that coefficient values differed between least- and most-disturbed sites in the Northern Appalachians $(p=0.056)$ and weak but suggestive evidence for the Southern Appalachians and the Northern Plains ( $p=0.11$ for each). In the three mountain ecoregions, the most-disturbed streams were narrower than the least-disturbed streams by an average of $16 \%$ in the Northern Appalachians, $12 \%$ in the Southern Appalachians, and 29\% in the Western Mountains; while in the two plains ecoregions the most-disturbed streams were wider than the least-disturbed streams by an average of $45 \%$ for the Southern Plains and 36\% for the Northern Plains (Table 8).

The Western Mountains was the one region, due in part to large sample size, in which there was convincing statistical evidence for a difference in channel width between disturbance classes. The pattern we found there-in which more-disturbed streams were consistently narrower than less-disturbed streams of comparable drainage areawas contrary to our expectations and to the common perception that channel widening is frequently associated with human disturbance in the western U.S. (e.g., Simon, 1989, 1995; Rosgen, 1994). Anthropogenic disturbances that are common in the western U.S. and that have been reported in the literature to be associated with channel widening include vegetation removal and bank trampling from cattle grazing (Kauffman et al., 1983; Kauffman and Krueger, 1984; Magilligan and McDowell, 1997; Kauffman et al., 2002) and uncontrolled grazing by wild ungulates (e.g., elk) following extirpation of wolves or other large carnivores (Beschta and Ripple, 2006, 2008), and augmentation of runoff and sediment supply associated with logging and logging road networks, land clearing, and development (Lyons and Beschta, 1983; Madej and Ozaki, 1996). The data for the Western Mountains clearly exhibit an association suggesting the opposite response of channel narrowing with increased human disturbance in 
most streams. Given that these same types of disturbances tend to reduce or eliminate woody riparian vegetation, however, the association of narrower channels with higher levels of human disturbance is consistent with results reported by several researchers on the basis of paired-reach studies that stream channel reaches with forested riparian zones are wider than adjacent or nearly adjacent reaches lacking riparian forest cover (Trimble, 1997; Nerbonne and Vondracek, 2001; Hession et al., 2003; Sweeney et al., 2004; Allmendinger et al., 2005). (However, Hey and Thorne, 1986 reported that woody riparian vegetation was associated with narrower channels in their multivariate DHG analysis of 62 stable gravel-bed rivers in the U.K.).

\subsubsection{Modeled effects of anthropogenic disturbance on channel width}

To shed further light on the relationship between anthropogenic disturbance and channel width, we modeled the effect of selected continuous disturbance metrics on the residuals from the final landscape effects model for each region (Table 6). Four broad metrics of land use intensity-percent of basin area in urban and agricultural land uses, road density $\left(\mathrm{km} / \mathrm{km}^{2}\right)$, and population density (persons/ $\mathrm{km}^{2}$ ), all of which were log-transformed-and one field-based metric of local riparian anthropogenic disturbance (see Methods) were included in the analysis. Table 9 presents the results of this analysis for all variables with a $p$-value of 0.05 or less when added to the landscape effects model. (For the three regions not included in the table, none of the disturbance metrics had $p<0.05$.) Table 9 also lists the 10th and 90th percentile values $\left(P_{10}\right.$ and $\left.P_{90}\right)$ of each disturbance metric within the specified region and bed material class (excluding zero values) and the magnitude of effect that a change from the $P_{10}$ to $P_{90}$ value has on the predicted residual from the landscape effects model. For example, in the Northern Appalachians (NAP), the $P_{10}$ and $P_{90}$ values of $L_{-} U R B$ among sampled sites with coarse bed material were, respectively, -1.40 and 0.75 , corresponding to percent urban cover values of 0.04 and 5.6\%; and the $P_{10}$ and $P_{90}$ values of the riparian disturbance index RIPDIS among all sampled streams in the region were 0.25 and 0.78 , respectively. The "Effect" column of Table 9 shows that for either of these variables added individually to the landscape effects model in Table 6 , the predicted bankfull width for a highly disturbed site ( $P_{90}$ value of disturbance metric) would be $18 \%$ ( $\left.L_{-} U R B\right)$ or $17 \%$ (RIPDIS) lower than a minimally disturbed site $\left(P_{10}\right.$ value of disturbance metric).
Of the five disturbance measures investigated, local riparian disturbance and two of the watershed disturbance metrics (percent agricultural land cover and road density) were each significantly associated with predicted bankfull width in three regions while percent urban land cover and population density were each significantly associated with bankfull width in two regions. Four of the five disturbance measures were significant in the Western Mountains, which had the largest number of sites, while two each were significant in the Northern and Southern Appalachians and the Temperate Plains and Xeric ecoregions and one was significant in the Coastal Plain. No significant associations between channel width and disturbance were found for the Upper Midwest or the Northern or Southern Plains. All but two of the significant associations were negative-that is, greater disturbance was associated with narrower stream channels.

Local riparian disturbance had a similar magnitude of effect in the Northern and Southern Appalachians, with a change from the $P_{10}$ to $P_{90}$ values of disturbance associated with a 16 to $17 \%$ decrease in predicted bankfull width. Percent urban landcover was associated with a similar magnitude of decrease in predicted bankfull width among coarse-bedded streams in the north, as was percent agricultural landcover among fine-bedded streams in the south (Table 9). In the Western Mountains, as in the Appalachians, local riparian disturbance was a significant predictor of bankfull width, but only for streams with fine bed material; width was not related to riparian disturbance for gravel-bed streams in the Western Mountains. Riparian disturbance was associated with an approximately onethird decrease in predicted bankfull channel width in the Western Mountains, roughly twice as large an effect as in the Appalachians. For coarse-bedded streams, percent agricultural land cover was associated with a $31 \%$ decrease in channel width in the Western Mountains, while population density and road density had somewhat smaller effects (Table 9).

In the Temperate Plains, both percent agricultural land use and road density were negatively associated with bankfull channel width (for fine and coarse-bedded streams, respectively), although the effect of agricultural land use was relatively small (a $10 \%$ reduction in bankfull width) because of the narrow range of this metric (1.82-1.98 for $P_{10}$ to $P_{90}$ values of $L \_A G$, or $66-95 \%$ agricultural land cover). Road density exhibited greater variability in this region $\left(P_{10}-P_{90}\right.$ range: $1.0-$ $2.6 \mathrm{~km} / \mathrm{km}^{2}$ ) and hence had a larger effect on predicted bankfull

Table 9

Regression results: residuals (observed minus predicted) from the predictive model fit (Table 6) vs. individual anthropogenic disturbance variables by region and bed material texture

\begin{tabular}{|c|c|c|c|c|c|c|c|c|c|c|c|}
\hline \multirow[t]{2}{*}{ Region } & \multirow{2}{*}{$\begin{array}{l}\text { Bed } \\
\text { material }\end{array}$} & \multirow[t]{2}{*}{ Variable $^{\mathrm{b}}$} & \multirow[t]{2}{*}{ Est. $^{\mathrm{c}}$} & \multirow[t]{2}{*}{ SE } & \multirow[t]{2}{*}{$p$-value } & \multicolumn{2}{|c|}{ Percentiles } & \multirow{2}{*}{$\begin{array}{l}\text { Effect } \\
\left(\mathrm{P}_{90} / \mathrm{P}_{10}\right)\end{array}$} & \multirow[t]{2}{*}{$r^{2}$} & \multirow[t]{2}{*}{ RMSE } & \multirow[t]{2}{*}{$N$} \\
\hline & & & & & & $\overline{P_{10}}$ & $P_{90}$ & & & & \\
\hline$\overline{\mathrm{NAP}}$ & $\mathrm{CS}$ & L_URB & -0.040 & 0.018 & 0.026 & -1.40 & 0.75 & $-18 \%$ & 0.087 & 0.118 & 57 \\
\hline NAP & $\mathrm{FN}+\mathrm{CS}$ & RIPDIS & -0.152 & 0.075 & 0.047 & 0.25 & 0.78 & $-17 \%$ & 0.052 & 0.133 & 77 \\
\hline SAP & FN & $L \_A G$ & -0.058 & 0.025 & 0.025 & 0.64 & 1.69 & $-13 \%$ & 0.117 & 0.095 & 43 \\
\hline SAP & CS & RIPDIS & -0.137 & 0.055 & 0.014 & 0.16 & 0.73 & $-16 \%$ & 0.046 & 0.129 & 131 \\
\hline CPL & $\mathrm{FN}+\mathrm{CS}$ & $L_{-} P O P D E N$ & 0.060 & 0.030 & 0.048 & 0.50 & 1.71 & $+18 \%$ & 0.045 & 0.159 & 87 \\
\hline TPL & FN & L_AG & -0.269 & 0.130 & 0.041 & 1.82 & 1.98 & $-10 \%$ & 0.030 & 0.168 & 139 \\
\hline TPL & CS & $L_{-} R D D E N$ & -0.341 & 0.147 & 0.026 & -0.00 & 0.42 & $-28 \%$ & 0.119 & 0.161 & 42 \\
\hline WMT & FN & RIPDIS & -0.374 & 0.152 & 0.016 & 0.21 & 0.70 & $-34 \%$ & 0.080 & 0.250 & 72 \\
\hline WMT & CS & L_POPDEN & -0.040 & 0.012 & 0.001 & -1.54 & 0.40 & $-16 \%$ & 0.035 & 0.170 & 293 \\
\hline WMT & CS & $L \_A G$ & -0.066 & 0.018 & 0.0004 & -2.00 & 0.45 & $-31 \%$ & 0.094 & 0.181 & 127 \\
\hline WMT & CS & L_RDDEN & -0.080 & 0.018 & $<.0001$ & -0.84 & 0.32 & $-19 \%$ & 0.048 & 0.176 & 386 \\
\hline XER & FN & $L_{-} U R B$ & 0.094 & 0.044 & 0.040 & -1.52 & 1.09 & $+76 \%$ & 0.116 & 0.248 & 37 \\
\hline XER & CS & $L \_R D D E N$ & -0.078 & 0.037 & 0.035 & -0.86 & 0.14 & $-17 \%$ & 0.038 & 0.204 & 116 \\
\hline
\end{tabular}

a Results are shown for all disturbance variables for which $(p<0.05)$. Sites with zero or missing values for a Disturbance variable (prior to log-transformation) were excluded from

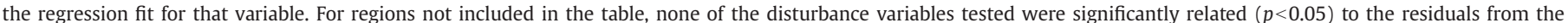
predictive model fit

b $L_{-} U R B=\log$ (\% urban land area), $L_{-} A G=\log \left(\%\right.$ agricultural land area), $L_{-} P O P D E N=\log$ (population density in persons $\left./ \mathrm{km}^{2}\right), L_{-} R D D E N=\log \left(\right.$ road density in $\left.\mathrm{km} / \mathrm{km}^{2}\right)$, and RIPDIS is an index of anthropogenic riparian disturbance varying between 0 and 1 (see text).

Value columns in table are as follows: The first three columns show the estimated regression parameter value, its standard error, and a $p$-value for the hypothesis that the true

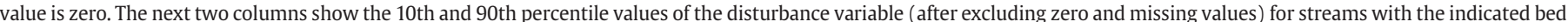

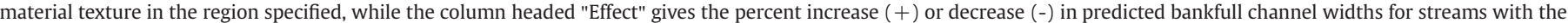

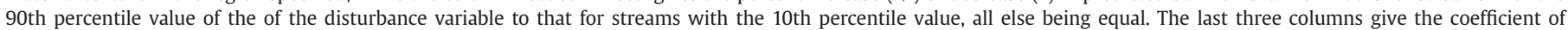
determination, root mean squared error, and number of observations used in each regression. 
widths, accounting for a $28 \%$ reduction in predicted bankfull width over the $P_{10}-P_{90}$ range among coarse-bedded streams. In the Coastal Plain, by contrast, population density was associated with an $\sim 18 \%$ increase in predicted channel width over the $P_{10}-P_{90}$ range. In the Xeric region, urban landcover was associated with substantially greater channel width among fine-bedded streams (a 76\% increase over the $P_{10}-P_{90}$ range), consistent with many previous studies that have examined the impact of urbanization on channel width (Booth and Jackson, 1997; Doll et al., 2002; Hession et al., 2003), while road density was weakly associated $\left(p=0.04, r^{2}=0.04\right)$ with smaller channel width among coarse-bedded streams (a 17\% decrease over the $P_{10}-P_{90}$ range; Table 9 ).

\section{Summary and conclusions}

We present predictive equations for bankfull width in nine large regions that comprise the conterminous United States based on a nationwide sample of streams with bankfull widths between 1 and $75 \mathrm{~m}$ and draining watersheds between 1 and 10,000 $\mathrm{km}^{2}$. These equations provide a useful first-order estimate of channel width, although we emphasize that they are no substitute for more detailed investigation for projects requiring accurate site-specific information. $\mathrm{DHG}_{\mathrm{wA}}$ equations differed between streams with dominantly fine bed material (silt/sand) and those with dominantly coarse bed material (gravel/cobble/boulder) in six of the nine analysis regions. Where $\mathrm{DHG}_{\mathrm{wA}}$ equations varied by sediment size, fine-bedded streams were consistently narrower than coarse-bedded streams over all or nearly all the range of basin drainage area. Our analysis showed that $\mathrm{DHG}_{\mathrm{wA}}$ equations developed for large geographic areas can provide a useful first-order estimate of expected bankfull channel width, particularly in the eastern United States; the four easternmost regions in our analysis had coefficients of determination $\left(r^{2}\right)$ of 0.60 or greater for the simplest form of the $\mathrm{DHG}_{\mathrm{wA}}$ equation using only drainage area as input. In the West, the predictive value of $\mathrm{DHG}_{\mathrm{wA}}$ equations based on drainage area alone was generally much poorer, with $r^{2}<0.50$ in all but one region. Enhanced DHG equations incorporating additional GIS-derived data for three landscape variables-mean annual precipitation, elevation, and mean reach slope-significantly improved equation fit and predictive value in several regions, most notably the Western Mountains and the Temperate Plains. However, in large geographic areas with highly variable topography, geology, and climate (such as the Western Mountains), developing DHG relationships over smaller, more homogeneous subregions can yield much better results for most subregions without having to incorporate additional variables besides drainage area.

Our analysis shows that bankfull width exhibits a detectable response to human disturbance in several regions. Where it differed between least-disturbed and most-disturbed sites within a region, the $\mathrm{DHG}_{\mathrm{wA}}$ exponent $\beta$ was consistently lower for the most-disturbed sites, as was the coefficient of determination for the $\mathrm{DHG}_{\mathrm{wA}}$ equation in most cases. Our data suggest that the dominant response of channel width to human disturbance in the United States is a reduction in bankfull width in streams with greater disturbance, particularly in the Western Mountains and the Appalachians, a response that would be consistent with anthropogenic incision. This is contrary to the pattern we expected to see based on previous observations of channel widening or enlargement reported in the literature for several common types of human disturbance, particularly urbanization, grazing, and clearcut logging (Lyons and Beschta, 1983; Booth and Jackson, 1997; Magilligan and McDowell, 1997). However, to the extent that anthropogenic disturbance in these regions involves removal of riparian trees, the negative association of channel width with disturbance is consistent with the widely reported observation that for small- to medium-sized catchments, stream channel reaches with grassy or nonwoody riparian vegetation tend to be narrower than adjacent forested reaches (Sweeney et al., 2004; Allmendinger et al., 2005). Other anthropogenic influences, such as channelization and flow diversions, could also contribute to the observed pattern. Further research is needed to resolve these issues by quantifying the relationships between channel characteristics and specific types of human disturbance, clarifying the role of spatial proximity and distribution of land use changes on in-channel adjustments, and elucidating the dominant mechanisms by which land use changes alter channel morphology. Understanding the temporal aspects of disturbance-response relationships-the lag time between initial disturbance and initial or maximum response and the recovery time for reestablishment of a new equilibrium or return to a previous state following disturbance-is also essential if we hope to understand and manage anthropogenic impacts to fluvial systems over broad spatial and temporal scales.

\section{Acknowledgments}

The research presented in this manuscript was undertaken at the USEPA's Western Ecology Division of the National Health and Environmental Effects Laboratory in Corvallis, OR, funded by the USEPA through the Environmental Monitoring and Assessment Program (EMAP; Cooperative Agreement CR 831682-01). We thank John VanSickle for advice on statistical analysis and Colleen Burch-Johnson for GIS assistance. This manuscript has been subjected to review by the National Health and Environmental Effects Research Laboratory's Western Ecology Division and approved for publication. Approval does not signify that the contents reflect the views of the Agency, nor does mention of trade names or commercial products constitute endorsement or recommendation for use.

\section{References}

Allmendinger, N.E., Pizzuto, J.E., Potter, N., Johnson, T.E., Hession, W.C., 2005. The influence of riparian vegetation on stream width, eastern Pennsylvania, USA Geological Society of America Bulletin 117 (1-2), 229-243.

Anderson, R.J., Bledsoe, B.R., Hession, W.C., 2004. Width of streams and rivers in response to vegetation, bank material, and other factors. Journal of the American Water Resources Association 40 (5), 1159-1172.

Beechie, T.J., 2001. Empirical predictors annual bed load travel distance, and implications for salmonid habitat restoration and protection. Earth Surface Processes and Landforms 26 (9), 1025-1034.

Beechie, T.J., Liermann, M., Pollock, M.M., Baker, S., Davies, J., 2006. Channel pattern and river-floodplain dynamics in forested mountain river systems. Geomorphology 78 (1-2), 124-141.

Beschta, R.L., Ripple, W.J., 2006. River channel dynamics following extirpation of wolves in northwestern Yellowstone National Park, USA. Earth Surface Processes and Landforms 31 (12), 1525-1539.

Beschta, R.L., Ripple, W.J., 2008. Wolves, trophic cascades, and rivers in the Olympic National Park, USA. Ecohydrology 1 (2), 118-130.

Booth, D.B., Jackson, C.R., 1997. Urbanization of aquatic systems: degradation thresholds, stormwater detection, and the limits of mitigation. Journal of the American Water Resources Association 33 (5), 1077-1090.

Castro, J.M., Jackson, P.L., 2001. Bankfull discharge recurrence intervals and regional hydraulic geometry relationships: patterns in the Pacific Northwest, USA. Journal of the American Water Resources Association 37 (5), 1249-1262.

Daly, C., Taylor, G.H., 2002. Development of new spatial grids of R factor and 10-yr EI30 for the conterminous United States. Internal EPA Report, NERL-LV. Spatial Climate Analysis Service, Oregon State University, Corvallis, Oregon.

Doll, B.A., Wise-Frederick, D.E., Buckner, C.M., Wilkerson, S.D., Harman, W.A., Smith, R.E Spooner, J., 2002. Hydraulic geometry relationships for urban streams throughout the Piedmont of North Carolina. Journal of the American Water Resources Association 38 (3), 641-651.

Dunne, T., Leopold, L.B., 1978. Water in Environmental Planning. W. H. Freeman Company, San Francisco. 818 pp.

Faustini, J.M., Kaufmann, P.R., 2007. Adequacy of visually classified particle count statistics from regional stream habitat surveys1. Journal of the American Water Resources Association 43 (5), 1293-1315.

Fenneman, N.M., 1946. Physical Divisions of the United States. U.S. Geological Survey, Reston, Virginia., Map Scale 1:7,000,000.

Ferguson, R.I., 1986. Hydraulics and hydraulic geometry. Progress in Physical Geography 10 (1), 1-31.

Golden, L.A., Springer, G.S., 2006. Channel geometry, median grain size, and stream power in small mountain streams. Geomorphology 78 (1-2), 64-76.

Herlihy, A.T., Larsen, D.P., Paulsen, S.G., Urquhart, N.S., Rosenbaum, B.J., 2000. Designing a spatially balanced, randomized site selection process for regional stream surveys: the EMAP mid-Atlantic pilot study. Environmental Monitoring and Assessessment 63, 95-113. 
Herlihy, A.T., Paulsen, S.G., Sickle, J.V., Stoddard, J.L., Hawkins, C.P., Yuan, L.L., 2008. Striving for consistency in a national assessment: the challenges of applying a reference-condition approach at a continental scale. Journal of the North American Benthological Society 27 (4), 860-877.

Hession, W.C., Pizzuto, J.E., Johnson, T.E., Horwitz, R.J., 2003. Influence of bank vegetation on channel morphology in rural and urban watersheds. Geology 31 (2), 147-150.

Hey, R.D., Thorne, C.R., 1986. Stable channels with mobile gravel beds. Journal of Hydraulic Engineering 112 (8), 671-689.

Jennings, M.E., Thomas Jr., W.O., Riggs, H.C., 1994. Nationwide Summary of U.S. Geological Survey Regional Regression Equations for Estimating Magnitude and Frequency of Floods for Ungaged Sites, 1993, pp. 94-4002.

Johnson, P.A., Fecko, B.J., 2008. Regional channel geometry equations: a statistical comparison for physiographic provinces in the eastern US. River Research and Applications 24 (6), 823-834.

Kauffman, J.B., Krueger, W.C., 1984. Livestock impacts on riparian ecosystems and streamside management implications...a review. Journal of Range Management 37 (5), 430-438.

Kauffman, J.B., Krueger, W.C., Vavra, M., 1983. Impacts of cattle on streambanks in northeastern Oregon. Journal of range management 36 (6), 683-685.

Kauffman, J.B., McDowell, P., Bayley, P., Li, H., Beschta, R., 2002. Research/evaluate restoration of NE Oregon streams. Bonneville Power Administration, U.S. Dept. of Energy BPA Report DOE/BP-00006210-1, Portland, OR.

Kaufmann, P.R., Faustini, J.M., Larsen, D.P., Shirazi, M.A., 2008. A roughness-corrected index of relative bed stability for regional stream surveys. Geomorphology 99 (14), 150-170.

Kaufmann, P.R., Levine, P., Robison, E.G., Seeliger, C., Peck, D.V., 1999. Quantifying physical habitat in wadeable streams. U.S. Environmental Protection Agency EPA/ 620/R-99/003, Washington, D.C.

Klemm, D.J., Blocksom, K.A., Fulk, F.A., Herlihy, A.T., Hughes, R.M., Kaufmann, P.R., Peck, D.V Stoddard, J.L., Thoeny, W.T., Griffith, M.B., Davis, W.S., 2003. Development and evaluation of a macroinvertebrate biotic integrity index (MBII) for regionally assessing Mid-Atlantic Highlands streams. Environmental Management 31 (5), 656-669.

Knighton, A.D., 1987. River channel adjustment-the downstream direction. In: Richards, K.S. (Ed.), River Channels: Environment and Process. Oxford Univ. Press, New York, pp. 95-128.

Knighton, D., 1998. Fluvial forms and Processes: A New Perspective. Arnold, New York 383 pp.

Leopold, L.B., 1994. A View of the River. Harvard University Press, Cambridge, MA. 298 pp

Leopold, L.B., Maddock Jr., T., 1953. The hydraulic geometry of stream channels and some physiographic implications. U.S. Geological Survey Professional Paper 282-B.

Leopold, L.B., Wolman, M.G., Miller, J.P., 1964. Fluvial Processes in Geomorphology. W. H. Freeman and Company, San Francisco, California.

Limpert, E., Stahel, W.A., Abbt, M., 2001. Log-normal distributions across the sciences: keys and clues. BioScience 51 (5), 341-352.

Lyons, J.K., Beschta, R.L., 1983. Land use, floods, and channel changes: upper Middle Fork Willamette River, Oregon (1936-1980) (Cascade Mountains). Water Resource Research 19 (2), 463-471.

Madej, M.A., Ozaki, V., 1996. Channel response to sediment wave propagation and movement, Redwood Creek, California, USA. Earth Surface Processes and Landforms 21 (10), 911-927.

Magilligan, F.J., McDowell, P.F., 1997. Stream channel adjustments following elimination of cattle grazing. Journal of the American Water Resources Association 33 (4), 867-878.

Mohamoud, Y.M., Parmar, R.S., 2006. Estimating streamflow and associated hydraulic geometry, the Mid-Atlantic Region, USA. Journal of the American Water Resources Association 42 (3), 755-768.

Moody, J.A., Meade, R.H., Jones, D.R., 2003. Lewis and Clark's observations and measurements of geomorphology and hydrology, and changes with time. U.S. Geological Survey Circular 1246, Reston, VA.

Nakamura, F., Swanson, F.J., 1993. Effects of coarse woody debris on morphology and sediment storage of a mountain stream system in western Oregon. Earth Surface Processes and Landforms 18 (1), 43-61.

Nakamura, F., Swanson, F.J., 1994. Distribution of coarse woody debris in a mountain stream, western Cascade Range, Oregon. Canadian Journal of Forest Research 24 (12), 2395-2403.

Nerbonne, B.A., Vondracek, B., 2001. Effects of local land use on physical habitat, benthic macroinvertebrates, and fish in the Whitewater River, Minnesota, USA. Environmental Management 28 (1), 87-99.

Omernik, J.M., 1987. Ecoregions of the conterminous United States. Annals of the Association of American Geographers 77 (1), 118-125.

Osterkamp, W.R., 1980. Sediment-Morphology Relations of Alluvial Channels, Proceedings of the Symposium on Watershed Management. American Society of Civil Engineers, Boise, Idaho, pp. 188-199.

Park, C.C., 1977. World-wide variations in hydraulic geometry exponents of stream channels: an analysis and some observations. Journal of Hydrology 33 (1-2), 133-146.

Parker, G., 1979. Hydraulic geometry of active gravel rivers. Journal of the Hydraulics Division, ASCE 105 (HY9, Proc.Paper, 14841), 1185-1201.
Pater, D.E., Bryce, S.A., Thorson, T.D., Kagan, J., Chappell, C., Omernik, J.M., Azevedo, S.H., Woods, A.J., 1998. Ecoregions of Western Washington and Oregon. U.S. Geological Survey, Reston, Virginia, Map Scale 1:1,350,000.

Paulsen, S.G., Hawkins, C.P., Sickle, J.V., Yuan, L.L., Holdsworth, S.M., 2008a. An invitation to apply national survey data to ecological research. Journal of the North American Benthological Society 27 (4), 1017-1018.

Paulsen, S.G., Mayio, A., Peck, D.V., Stoddard, J.L., Tarquinio, E., Holdsworth, S.M., Sickle, J.V., Yuan, L.L., Hawkins, C.P., Herlihy, A.T., Kaufmann, P.R., Barbour, M.T., Larsen, D.P., Olsen, A.R., 2008b. Condition of stream ecosystems in the US: an overview of the first national assessment. Journal of the North American Benthological Society 27 (4), 812-821.

Peck, D.V., Herlihy, A.T., Hill, B.H., Hughes, R.M., Kaufmann, P.R., Klemm, D.J., Lazorchak, J.M., McCormick, F.H., Peterson, S.A., Ringold, P.L., Magee, T., Cappaert, M., 2006. Enivironmental monitoring and assessment program-surface waters: western pilot study field operations manual for wadeable streams. U.S. Environmental Protection Agency EPA 620/R-06/003, Washington, D.C

Ramsey, F.L., Schafer, D.W., 2002. The Statistical Sleuth: A Course in Methods of Data Analysis. Duxbury, Pacific Grove, California. 742 pp.

Rosenfeld, J.S., Post, J., Robins, G., Hatfield, T., 2007. Hydraulic geometry as a physical template for the river continuum: application to optimal flows and longitudinal trends in salmonid habitat. Canadian Journal of Fisheries and Aquatic Sciences 64 (5), 755-767.

Rosgen, D.L., 1994. A classification of natural rivers. Catena 22, 199-169.

Seaber, P.R., Kapinos, F.P., Knapp, G.L., 1987. Hydrogeologic Unit Maps. U.S. Geological Survey Water Supply Paper 2294, Denver, Colorado.

Simon, A., 1989. A model of channel response in disturbed alluvial channels. Earth Surface Processes and Landforms 14 (1), 11-26.

Simon, A., 1995. Adjustment and recovery of unstable alluvial channels: identification and approaches for engineering management. Earth Surface Processes and Landforms 20 (7), 611-628.

Simons, D.B., Albertson, M.L., 1963. Uniform water conveyance channels in alluvial material. Transactions of the American Society of Civil Engineers 128, 65-107.

Soar, P.J., Thorne, C.R., 2001. Channel restoration design for meandering rivers. U.S. Army Corps of Engineers, Engineer Research and Development Center ERDC/CHL CR-011, Vicksburg, Mississippi.

Stevens, D.L., Olsen, A.R., 1999. Spatially restricted surveys over time for aquatic resources. Journal of Agricultural, Biological, and Environmental Statistics 4, 415-428.

Stevens, D.L., Olsen, A.R., 2004. Spatially-balanced sampling of natural resources. Journal of American Statistical Association 99 (465), 262-278.

Stoddard, J.L., Peck, D.V., Paulsen, S.G., Van Sickle, J., Hawkins, C.P., Herlihy, A.T., Hughes, R.M., Kaufmann, P.R., Larsen, D.P., Lomnicky, G., Olsen, A.R., Peterson, S.A., Ringold, P.L., Whittier, T.R., 2005. An ecological assessment of western streams and rivers. U.S. Environmental Protection Agency EPA 620/R-05/005, Washington, D.C.

Sweeney, B.W., Bott, T.L., Jackson, J.K., Kaplan, L.A., Newbold, J.D., Standley, L.J., Hession, W.C., Horwitz, R.J., 2004. Riparian deforestation, stream narrowing, and loss of stream ecosystem services. Proceedings of the National Academy of Sciences 101 (39), 14132-14137.

Sweet, W.V., Geratz, J.W., 2003. Bankfull hydraulic geometry relationships and recurrence intervals for North Carolina's Coastal Plain. Journal of the American Water Resources Association 39 (4), 861-871.

Trimble, S.W., 1997. Stream channel erosion and change resulting from riparian forests. Geology 25 (5), 467-469.

U.S. Census Bureau, 1990. TIGER Line Maps: 1990 U.S. Counties. U.S. Department of Commerce, U.S. Census Bureau, Washington, D.C.

U.S. Census Bureau, 2001. U.S. Census Bureau Online Information. U.S. Department of Commerce, U.S. Census Bureau, Washington, D.C. http://www.census.gov/main/ www/cen2000.html.

U.S. Environmental Protection Agency (USEPA), 2006. Wadeable streams assessment: a collaborative assessment of the nation's streams. EPA 841-B-06-002, Washington, D.C.

U.S. Forest Service (USFS), 1995. A Guide for Field Identification of Bankfull Stage in the Western United States. DVD, $31 \mathrm{~min}$. Stream Systems Technology Center, USDA Forest Service, Fort Collins, CO 80526.

U.S. Forest Service (USFS), 2003. Identifying Bankfull Stage in Forested Streams in the Eastern United States. DVD, 46 min. Stream Systems Technology Center, USDA Forest Service, Fort Collins, CO 80526.

Vannote, R.L., Minshall, G.W., Cummins, K.W., Sedell, J.R., Cushing, C.E., 1980. The river continuum concept. Canadian Journal of Fisheries and Aquatic Sciences 37 (1), 130-137.

Waite, I.R., Herlihy, A.T., Larsen, D.P., Klemm, D.J., 2000. Comparing strengths of geographic and nongeographic classifications of stream benthic macroinvertebrates in the MidAtlantic Highlands, USA. Journal of the North American Benthological Society 19 (3), 429-441.

Whittier, T.R., Stoddard, J.L., Larsen, D.P., Herlihy, A.T., 2007. Selecting reference sites for stream biological assessments: best professional judgment or objective criteria. Journal of the North American Benthological Society 26 (2), 349-360.

Wolman, M.G., Gerson, R., 1978. Relative scales of time and effectiveness of climate in watershed geomorphology. Earth Surface Processes 3, 189-208. 